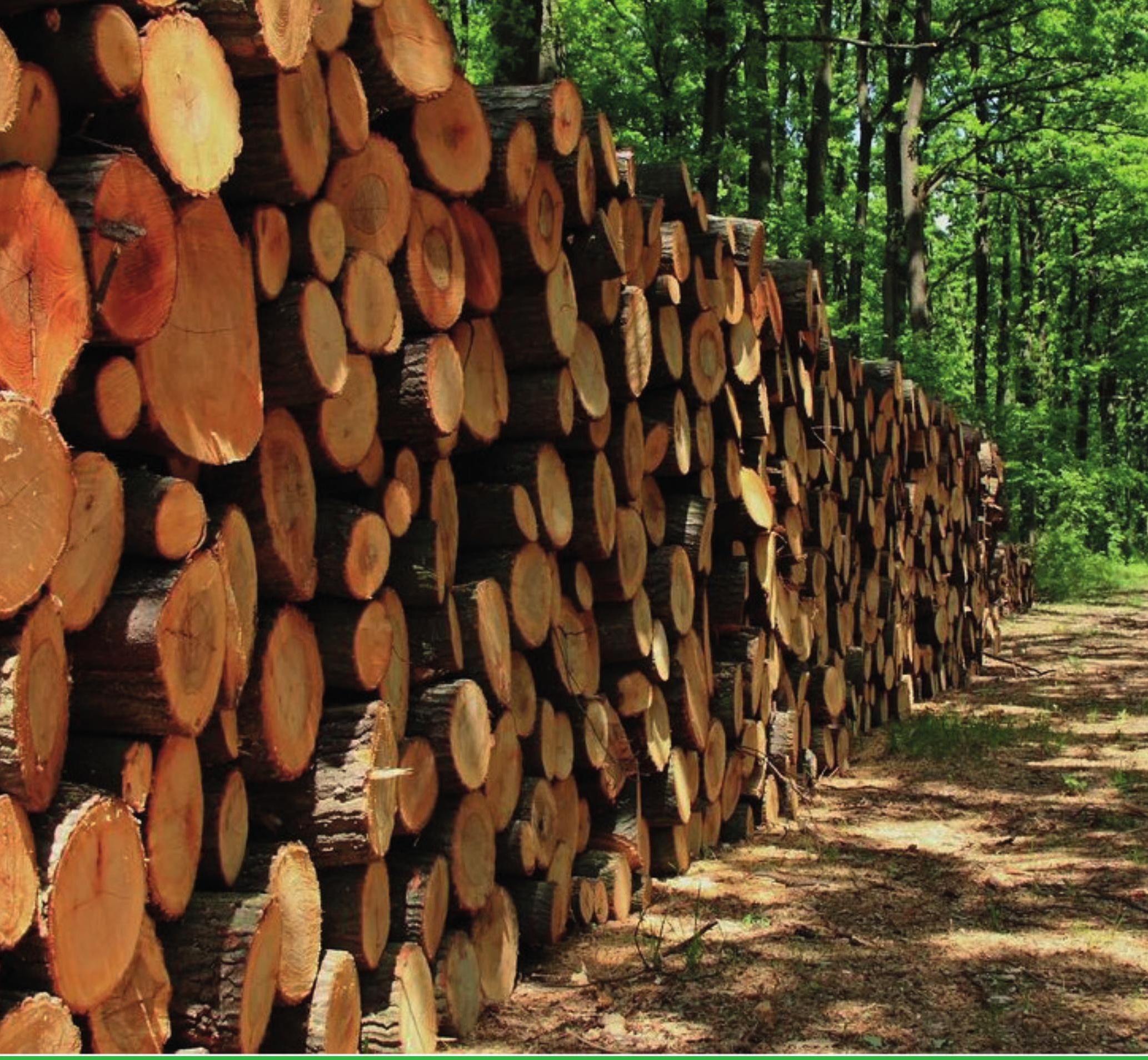

\title{
Potential of valorising local wood in construction sector in Gelderland
}

Iris Vural Gursel, Jan van Dam, Wolter Elbersen, Edwin Hamoen, Mart-Jan Schelhaas, Bas Lerink,

Gert-Jan Nabuurs, Remco Kranendonk, and Marie-Jose Smits

$\square \quad \begin{aligned} & \text { WAGENINGEN } \\ & \text { UNIVERSITY \& RESEARCH }\end{aligned}$ 



\section{Potential of valorising local wood in construction sector in Gelderland}

Authors: Iris Vural Gursel ${ }^{1}$, Jan van Dam ${ }^{1}$, Wolter Elbersen ${ }^{1}$, Edwin Hamoen ${ }^{1}$, Mart-Jan Schelhaas ${ }^{2}$, Bas Lerink ${ }^{2}$, Gert-Jan Nabuurs ${ }^{2}$, Remco Kranendonk ${ }^{2}$, and Marie-Jose Smits ${ }^{3}$

Institute: 1. Wageningen Food and Biobased Research

2. Wageningen Environmental Research

3. Wageningen Economic Research

This research project has been carried out by Wageningen Research commissioned by the Dutch Ministry of Agriculture, Nature and Food Quality (project number Project KB-34-012-002). 
WFBR Project number: 6224088700

Version: Final

Reviewer: Martien van den Oever

Approved by: Jan Jetten

Subsidised by: the Dutch Ministry of Agriculture, Nature and Food Quality

Commissioned by: the Dutch Ministry of Agriculture, Nature and Food Quality

This report is: Public

The research that is documented in this report was conducted in an objective way by researchers who act impartial with respect to the client(s) and sponsor(s). This report can be downloaded for free at https://doi.org/10.18174/560354 or at www.wur.eu/wfbr (under publications).

(c) 2021 Wageningen Food \& Biobased Research, institute within the legal entity Stichting Wageningen Research.

The client is entitled to disclose this report in full and make it available to third parties for review. Without prior written consent from Wageningen Food \& Biobased Research, it is not permitted to:

a. partially publish this report created by Wageningen Food \& Biobased Research or partially disclose it in any other way;

b. use this report for the purposes of making claims, conducting legal procedures, for (negative) publicity, and for recruitment in a more general sense;

c. use the name of Wageningen Food \& Biobased Research in a different sense than as the author of this report.

PO box 17, 6700 AA Wageningen, The Netherlands, T + 31 (0)317 4800 84, E info.wfbr@wur.nl, www.wur.eu/wfbr.

All rights reserved. No part of this publication may be reproduced, stored in a retrieval system of any nature, or transmitted, in any form or by any means, electronic, mechanical, photocopying, recording or otherwise, without the prior permission of the publisher. The publisher does not accept any liability for inaccuracies in this report. 


\section{Contents}

$\begin{array}{ll}\text { Abstract } & 4\end{array}$

1 Introduction $\quad 5$

2 Defining the state-of-the-art $\quad 7$

2.1 The current role of biobased building materials in building industry in Gelderland 7

2.2 Current production and use of bio-based building materials from wood in Gelderland/Netherlands $\quad 9$

2.3 Different stakeholders along the value chain 12

2.4 Current availability of wood and use of local wood in the building industry 13

3 Defining the potential of biobased building materials for improved sustainability and circularity in Gelderland

3.1 Enabling and restricting framework, governance and policy for biobased building materials

$\begin{array}{lll}3.1 .1 & \text { EU level } & 17\end{array}$

3.1.2 National policies 18

3.1.3 Province of Gelderland 19

3.1.4 Reflection on policies and strategic choices $\quad 21$

3.2 Hurdles faced by biobased building materials in the market 22

3.2.1 Approach $\quad 22$

3.2.2 Outcome of stakeholder interviews $\quad 22$

3.2.3 'Green' building market development 24

3.3 Circularity consideration for wooden building materials 25

3.4 Maximum potential availability of wood for use in building industry that can be sustainably harvested in Gelderland/Netherlands 28

3.4.1 Introduction $\quad 28$

$\begin{array}{ll}3.4 .2 & \text { Methods and data }\end{array}$

$\begin{array}{lll}3.4 .3 & \text { Results } & 29\end{array}$

$\begin{array}{ll}3.4 .4 & \text { Discussion }\end{array}$

$\begin{array}{lll}3.5 & \text { Matching wood types with applications } & 40\end{array}$

3.5.1 Matrix wood for construction materials $\quad 40$

$\begin{array}{ll}\text { 3.5.1.1 Timber } & 40\end{array}$

$\begin{array}{ll}\text { 3.5.1.2 Panels and boards } & 41\end{array}$

3.5.2 Species' potentials for the industry in Gelderland $\quad 42$

$\begin{array}{lll}3.6 & \text { SWOT Analysis } & 43\end{array}$

4 Conclusions $r$

$\begin{array}{lr}\text { Acknowledgements } & 48\end{array}$ 


\section{Abstract}

This report brings insights into the potential of valorising local lignocellulosic biomass of wood in the province of Gelderland at construction industry. The use of locally available wood can make a crucial contribution to the future mix of raw materials for the building industry. This is supportive of reaching targets to combat climate change and contributes to circular economy by storing carbon and reducing dependence on non-renewable sources.

An analysis was made of the current situation in Gelderland, including the current use and availability of biobased materials, and a mapping of the various stakeholders along the value chain. Current policies influencing the use of biobased material in the construction sector were reviewed. Through a series of interviews of different actors along the value chain, the hurdles and gaps faced for the increased implementation of biobased building materials and for increasing the circularity of the building industry were identified. Furthermore, the current and potential availability of wood that can be sustainably sourced from the province of Gelderland was identified through a study with the EFISCEN Space forest resource model, combined with a literature review on the potential of different species to be used in the construction sector. Possibilities of matching the local wood species to the demands of the building applications were analysed. Finally, a SWOT analysis was carried out to identify the main issues and needs such as knowledge, infrastructure, chains, collaborations, policy, technology for the valorisation of local wood in the construction sector. Subsequently recommendations were provided for next possible actions and the role of the different actors in the chain to address these needs.

Being the most wooded province of the country and hosting a significant construction industry, makes Gelderland an advantageous spot to explore this opportunity. Furthermore, the knowledge domain in the province and relevant national and provincial policy incentives support the circular economy transition. There is knowledge on biobased products within WUR and other knowledge partners in the province. At the other hand, European policy towards renewable energy, especially Renewable Energy Directive, diverts biomass towards energy production. Moreover, Dutch policies towards nature conservation imposes restrictions on harvesting wood. Furthermore the large scale availability of wood abroad such as North and East Europe, make Dutch wood relatively more expensive. Also the local infrastructure in making wood based building materials is limited. Yet, there is increasing demand for locally produced wood products. Improvement of the supply and utilization of local wood calls for strengthened communication and collaboration between many partners (feedstock suppliers, technology providers, knowledge an testing institutes/centres, industry, cluster organisations and municipalities). Furthermore, there is requirement of investment to stimulate development of necessary infrastructure and innovation to develop local value chains and to increase the number and volume of the applications. 


\section{Introduction}

The construction sector is responsible for a significant share of greenhouse gas (GHG) emissions (about 35\%) and primary raw material use (about 50\%) in the Netherlands. ${ }^{1}$ Currently, the majority of the building materials that are used are non-renewable and at the end of its lifecycle, most parts of the building cannot be reused (linear approach). This results in demand of new raw materials to be used and piling up of waste. A large proportion of waste in the Netherlands (approximately 40\%) involves construction and demolition waste. In 2015, the Paris Agreement set a challenging goal to fight against climate change. Furthermore, in 2019, the European Commission adopted a comprehensive report on the implementation of the Circular Economy Action Plan. ${ }^{2}$ A circular economy reduces pressure on natural resources, and is seen as a precondition for achieving the climateneutrality target by 2050 . The Commission will launch concrete actions on Construction and building to promote circularity principles for buildings addressing the sustainability performance of construction products. This policy agenda puts pressure on the construction sector to transit towards a more sustainable and circular approach.

Use of bio-based building materials can and will play an important role in this transition. They have a real gain compared to conventional building materials by allowing carbon to be stored through years of application and recycling, whereas conventional building materials (such as steel and concrete) are produced with a high energy input and responsible for large amount of GHG emissions.

Supporting this transition, the Dutch government launched a Government-wide programme "A Circular Economy in the Netherlands by $2050^{\prime \prime}$, which states the ambition to reduce primary raw materials (minerals, fossil and metals) use by $50 \%$ and to realise a circular economy by 2050 . "Biomass and food" and "Construction sector" are identified as 2 of the 5 priorities that are important for the Dutch economy and that have a large impact on the environment. One of the strategic goals is: In cases in which new raw materials are needed, fossil-based, critical and non-sustainably produced raw materials are replaced by sustainably produced, renewable, and generally available raw materials.

Wood is a versatile biomass resource that can be used as a raw material to produce a wide range of products in the pulp and paper industry, furniture and timber industry as well as in new innovative applications in the bio-based economy (such as wood-plastic composites). Furthermore, the residues from the processing of wood can be utilized for energy purposes. Cascading use of wood can be an important contributor to the development of a circular bio-based economy where more value is generated with less resource use. It is also an important way forward to reduce pressure on forests and to meet increasing demand for sustainable products. At EU level, the Action Plan for a Circular Economy and the Bioeconomy Strategy promote the cascading use of biomass. However, the European and also national (Dutch) regulations subsidize energy production from biomass including wood, which may promote a shift from material to energy use. This goes against the principles of cascading use where it is aimed that woody biomass is preferably processed into a product and this product is used at least once more to produce materials before it is used for energy recovery purposes. $^{3}$

Being the most wooded province of the country and hosting a significant construction industry, makes Gelderland an advantageous spot to explore the opportunity of valorising it further in the local construction industry. Furthermore, according to the national monitor of The Netherlands Enterprise Agency (RVO), Gelderland is leader in Biobased Economy which provides the necessary knowledge and technology foundation. Biobased raw materials form an integral part of the circular economy agenda of Gelderland. Recently the province published the Circular Atlas Gelderland ${ }^{4}$ where possible reduction options per sector are identified.

\footnotetext{
${ }^{1}$ Government of the Netherlands, 2016. A Circular Economy in the Netherlands by 2050.

${ }^{2}$ European Commission, 2019. Report on the implementation of the Circular Economy Action Plan. COM (2019) 190.

${ }^{3}$ WWF, 2016. Mapping Study on Cascading Use of Wood Products.

${ }^{4}$ Provincie Gelderland, 2019. Circulaire Atlas Gelderland.
} 
For the construction sector use of biobased materials is included as one of the three priority options considered. Their current challenge involves upscaling the use of biobased building materials.

The goal of this project funded by Dutch Ministry of Agriculture, Nature and Food Security is to analyse the potential of valorising local wood in the construction sector in the province of Gelderland and to provide answer to the questions:

- What application possibilities exist for the use of wood in bio-based building materials?

- How linked is the building materials industry to the local biomass supply?

- What is the current and potential availability of wood in Gelderland?

- How could the biobased uptake of the construction industry in Gelderland be improved?

- What are the hurdles faced and how can they be overcome?

- How could the demand and supply be better matched, from a building industry standpoint (demands of different applications) and from the wood production standpoint (characteristics of the harvested local wood types)?

- What are needed (knowledge, technology, infrastructure, collaborations, policy, ..) to realise the ambitions, overcome challenges? 


\section{Defining the state-of-the-art}

\subsection{The current role of biobased building materials in building industry in Gelderland}

The building sector is under pressure to reduce their impact on the environment. The requirements on nitrogen ${ }^{5}$ and $\mathrm{CO}_{2}$ emissions reduction are causing many projects to be delayed in building industry. Nitrogen emissions ( $\mathrm{NO}_{x}$ and $\mathrm{NH}_{3}$ ) affect the biodiversity in the Natura 2000 regions by nitrogen depositions. Within $5 \mathrm{~km}$ from those areas (Figure 1) restrictions on new building activities have been made. For the province of Gelderland this means that the building sector is significantly affected. Building permissions and licensing for new housing or infrastructure projects are often postponed or cancelled. Another concern for the building sector is the pollution of soils with PFAS (per- and polyfluoroalkyl substances). The requirement $(<0.1 \mathrm{mg} / \mathrm{kg})$ hinders many projects that require earthworks and dredging. The increased use of wood as a renewable resource in building industry could contribute to tackling this challenge.

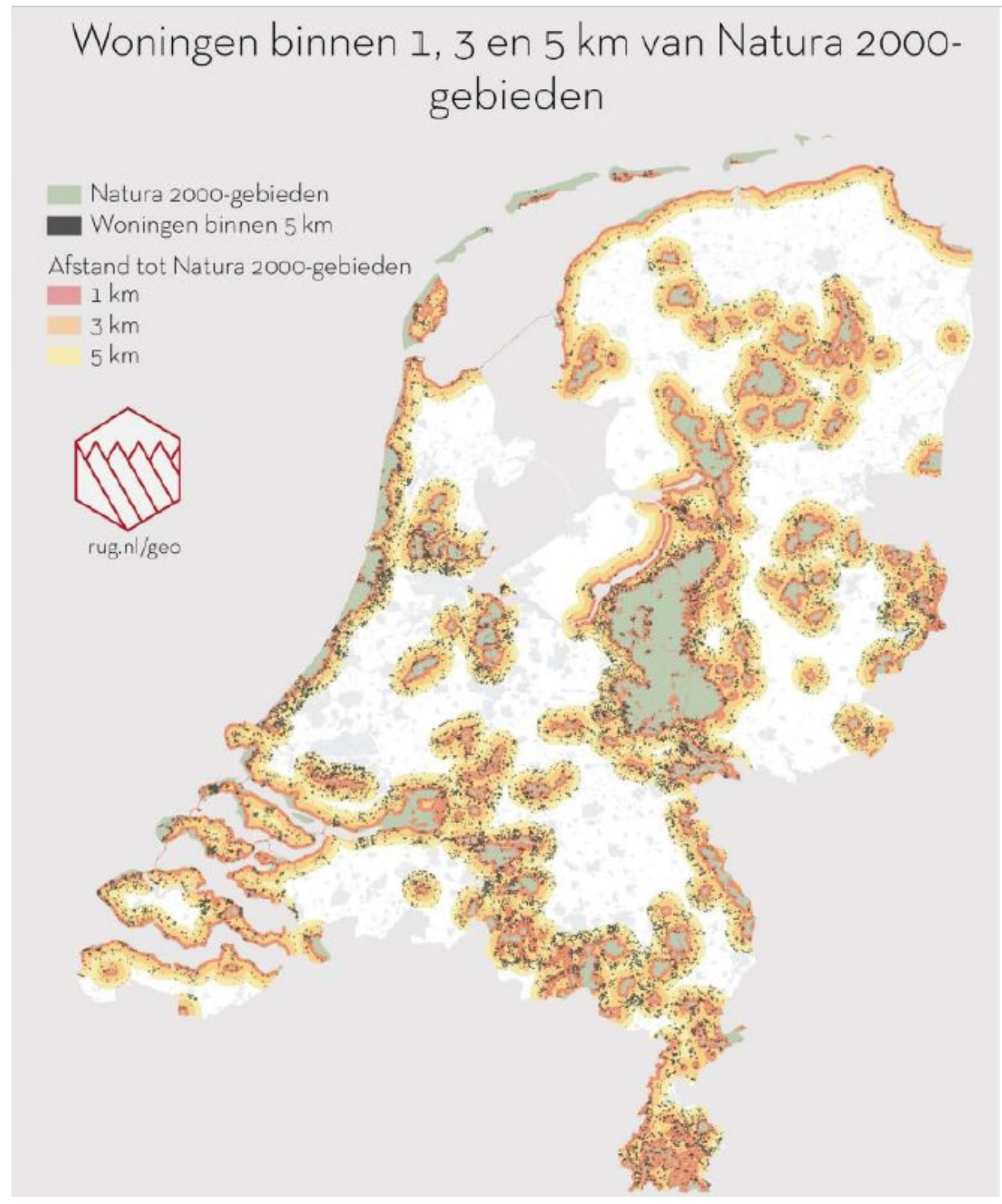

\footnotetext{
${ }^{5}$ EIB - Stikstof problematiek, effecten op realisatie van bouwprojecten op korte en middellange termijn, 2019

${ }^{6} \mathrm{RUG} . \mathrm{nl} / \mathrm{geo}$
} 
The Dutch transition policy agenda, as defined by the "Klimaat enveloppe" , refers to the use of biobased materials for building in the transition towards a circular and $\mathrm{CO}_{2}$ neutral economy. The building industry is one of the sectors that is using the highest volumes of raw materials. Options to reduce the high environmental footprint of the building sector can be found in increased circularity to reduce demand of primary raw materials and use of more renewable raw materials in cases in which new raw materials are needed. Most common used building materials (e.g. concrete, steel, glass, aluminium, synthetic polymers) contribute significantly to greenhouse gas emissions, especially in their production phase. The carbon footprint of a construction applying biobased materials is significantly lower, as carbon is stored and may be considered as a temporarily 'negative emission'. Ecological or green building ${ }^{8}$ and the use of renewable and biobased building materials has received increasing attention in the past decade from a selected group of architects and constructors. Despite this, wood frame construction remains a small niche ${ }^{9}$ in the building industry. In recent years several examples of wood frame building and straw bale construction projects have been realized on several locations, also in the Province of Gelderland. The current contribution of wood as construction materials in the Dutch building sector is restricted (estimated to be just $2 \%$ on weight basis) ${ }^{10}$, but its potential for future building is considered very promising. The question then arises whether sufficient wood can be made available to supply the increasing demand. Currently most of the timber, sawn wood products and wood based panels are being imported from other EU countries (e.g. Sweden, Finland, Germany, France) or outside EU for tropical timber.

Wood and wood products find many different uses in the building sector. Building activities can be residential housing (new, renovation and restauration), or non-residential construction (industry, utilities, lodgings, recreational housing) and civil engineering (infrastructure, road and waterworks). Each type of building project may have different conditions and specifications for the materials performance and each wood species has typical quality features ${ }^{11}$.

The wood market is supplied by the timber trade, who are organized in the Dutch sector association for timber companies: VVNH (Koninklijke Vereniging van Nederlandse Houtondernemingen ${ }^{12}$ ).

Information on companies active in the wood processing industries can be found at Houtnieuws ${ }^{13}$. The carpentry industries are organized in the industry association NBVT (Nederlandse Branchevereniging voor de Timmerindustrie ${ }^{14}$ ). The wood industry organizations are promoting the use of FSC and PEFC certified wood and wood products. The association for building and construction industries (Bouwend Nederland ${ }^{15}$ ) is very large where the timber industries are only a small sector. For the future sustainable developments in the building industries, however, industrialized construction with wood is considered as one of the most promising options, together with innovations for modular concepts (design-to-rebuild) and circular material use ${ }^{16}$. The province of Gelderland is well represented with prominent member companies in each organization. Several outstanding companies for use of wood in building and construction are based in the province.

${ }^{7}$ www.pianoo.nl/nl/themas/maatschappelijk-verantwoord-inkopen-duurzaam-inkopen/ontwikkelingen/klimaatenveloppeimpuls

${ }^{8}$ Green building is defined as a building designed to be ecologically correct by using resources efficiently, using internal recycling, renewable energy sources, recyclable or biodegradable construction materials, and blending in with the local environment, particularly in out-of-town locations with the aim to reduce the overall impact of the built environment on human health and the natural environment.

9 Jan van Dam, Martien van den Oever - Catalogus Biobased Bouwmaterialen 2019, Het groene en circulaire bouwen. Groene grondstoffen 15, Propress, Wageningen 2019.

${ }^{10}$ https://circulairebouweconomie.nl/wp-content/uploads/2019/07/CBE-Eindrapportage-potentie-biobased-materialen-NIBEjuli-2019.pdf

11 www.houtdatabase.nl/?q=hout/bouw

12 www.vvnh.nl

13 www.houtwereld.nl/

14 www.nbvt.nl

15 www.bouwendnederland.nl/

${ }^{16}$ www.bouwendnederland.nl/actueel/nieuws/11177/bouwlab-live-industrieel-bouwen-met-hout 


\subsection{Current production and use of bio-based building materials from wood in Gelderland/Netherlands}

After harvesting of the roundwood, a number of processing steps are important for the use of the various types of wood in construction applications. After seasoning, which will reduce the moisture content to about $20 \%$, the logs need debarking. In the saw mill the stems are sawn to various sizes, and dried. Depending on the wood quality and intended application, wood must be further processed, dried, reduced, sawn, sanded and / or planed (Figure 2). Subsequently, in the carpentry factory, the loose parts must be formed into a product (nailing, screwing or gluing) or the chips or loose fibers must be pressed into a sheet or moulded part, often using synthetic glues (Urea Formaldehyde - UF, Phenol Formaldehyde - PF, Melamine Urea Formaldehyde - MUF, Methylene Diphenyl Diisocyanate MDI). It must be noted that in the wood working process a significant part (estimated $50 \%$ ) is discarded as bark, saw dust, trimmings, split wood, shavings, sander dust and cut-offs. These are either left in the field or used for fuel or animal bedding.

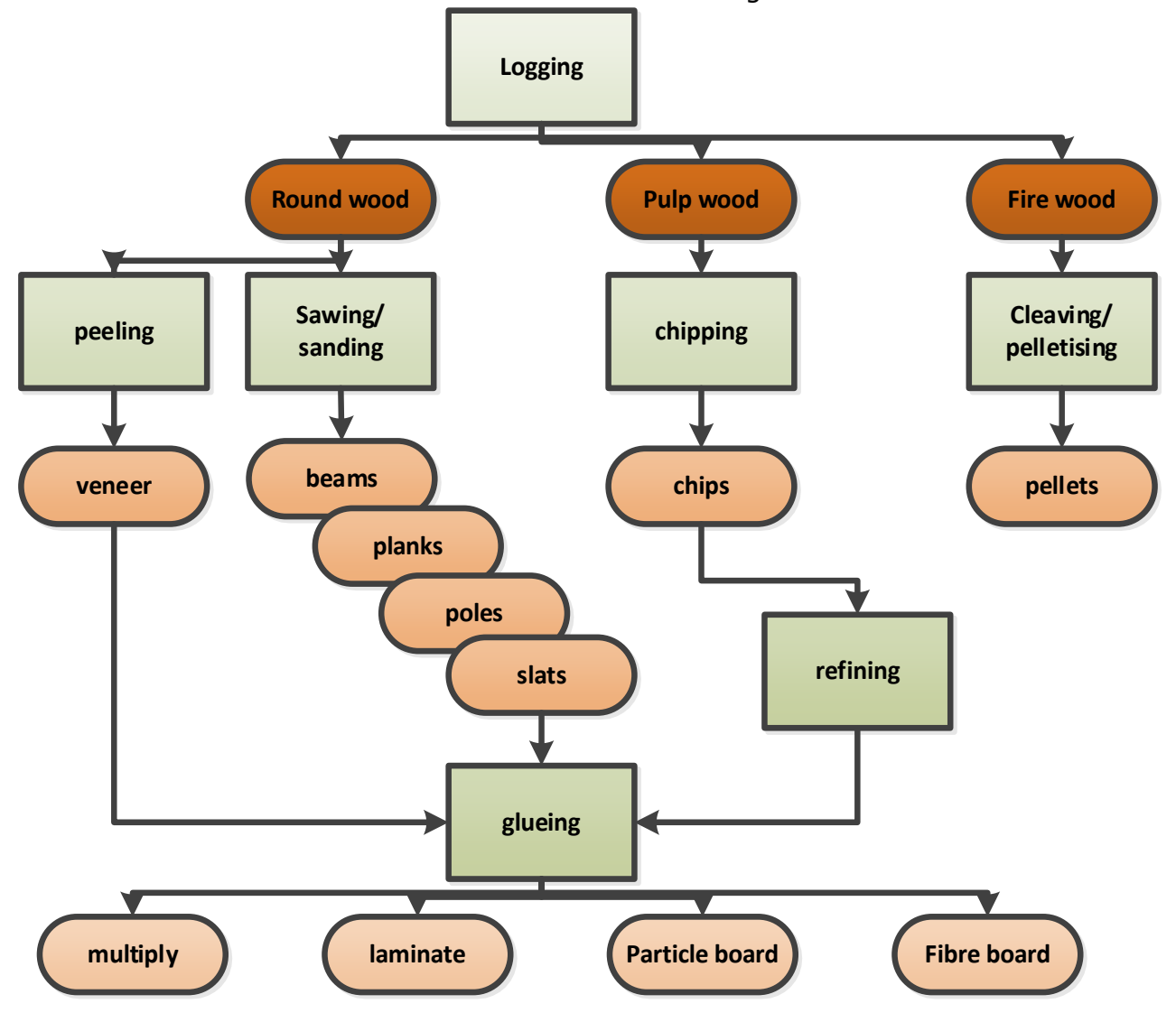

Figure 2

Wood processing steps

Wood based products are being used in many different applications for building and construction. Besides constructive or decorative purposes wood finds many uses in the building process as packaging (crates, pellets) or temporary support (formwork, moulds). Different wood sources yield a wide range of wood qualities that may find use in building and construction. In Table 1 the uses of local wood species is listed. Not all species that are listed in the European wood types allowed for structural timber (EN 1912 ${ }^{17}$ ) are indigenous species, but will grow in European forests, e.g. Eucalyptus, Douglas pine, etc. Imported tropical hardwood species are excluded from this list.

Wood qualities are related to the functional properties required for an application. Visual properties (texture, colour) are important for the purpose of decoration, while mechanical properties ${ }^{18}$ (stiffness, strength, hardness) are most important for load bearing constructions.

\footnotetext{
${ }^{17}$ EN 1912:2012 Structural Timber - Strength classes - Assignment of visual grades and species

${ }^{18}$ https://www.houtdatabase.nl/infobladen/Infoblad_Houteigenschappen-Sterktegegevens.pdf
} 
For building applications the Eurocode (according to EN $1995-1-1^{19}$ and EN $338^{20}$ ) are used for calculations of wood constructions. The dimensions of sawn wood products are dependent on the diameter and length of the roundwood. Not all wood species have such long straight stems suitable for manufacturing of long beams and planks. Characteristics of wood species differ in the densities, colour, and nervature (consistency and orientation) of the wood. The ratio sapwood and heartwood, and the presence of knots and defects can complicate the wood workability. The wood quality is also related to the way the wood is sawn and dried. As wood may shrink and swell with moisture and changing air humidity the dimensional stability is affected. Warping, bending and cracking may occur. The durability class (EN $1912^{17}$, Table 1 ) or the sensitivity of wood types to degradation due to environmental factors (moisture, light, and fungal attack) is determining the suitability for construction purposes indoor or outdoor where class 1 is most durable and class 5 is most sensitive.

Table 1

Properties of (indigenous) wood species suitable as timber ${ }^{21}$ (EN 1912 structural timber; hard wood species and soft wood species).

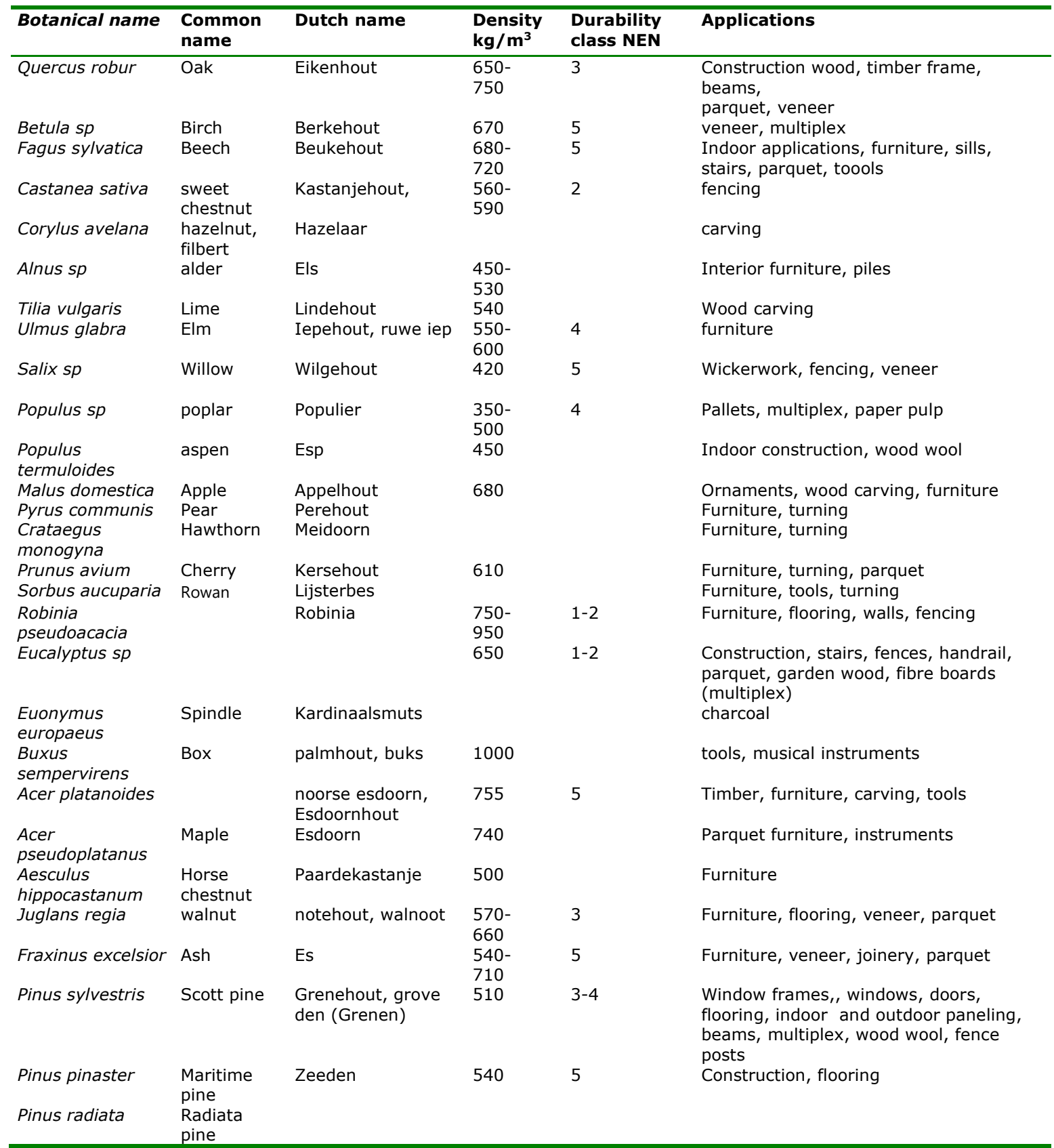

\footnotetext{
${ }^{19}$ EN 1995-1-1 Eurocode 5: Design of timber structures - Part 1-1: General - Common rules and rules for buildings

${ }^{20}$ EN 338:2016 Structural timber - Strength classes

${ }^{21}$ https://www.houtinfo.nl/toepassingen/houtdatabase
} 


\begin{tabular}{|c|c|c|c|c|c|}
\hline Pinus nigra & & Pijnboomhout, den & $\begin{array}{l}420- \\
670\end{array}$ & $4-5$ & Indoor applications, pallets, crates \\
\hline Abies alba & Fir & Zilver spar & & & \\
\hline Picea abies & Spruce & Fijnspar (Vuren) & 460 & 4 & $\begin{array}{l}\text { Window frames, facades, windows, } \\
\text { doors, stairs, flooring, cupboards, } \\
\text { formwork, moulding, multiplex, particle } \\
\text { board }\end{array}$ \\
\hline Larix decidua & Larch & Lariks, lork & $\begin{array}{l}500- \\
590\end{array}$ & 3 & $\begin{array}{l}\text { Load bearing constructions, window } \\
\text { frames, windows, cladding, indoor } \\
\text { paneling, stairs, } \\
\text { struts, roof tracks, fencing }\end{array}$ \\
\hline $\begin{array}{l}\text { Pseudotsuga } \\
\text { menziessii }\end{array}$ & $\begin{array}{l}\text { Douglas } \\
\text { pine }\end{array}$ & & 530 & $3-4$ & timber, beams, planks, poles, multiplex \\
\hline Taxus baccata & Yew & $\begin{array}{l}\text { Taksushout } \\
\text { (venijnboom) }\end{array}$ & 670 & & Furniture, veneer \\
\hline Thuja plicata & $\begin{array}{l}\text { Western } \\
\text { red cedar }\end{array}$ & & $\begin{array}{l}350- \\
380\end{array}$ & 2 & $\begin{array}{l}\text { Outdoor applications, poles, planking, } \\
\text { shingles }\end{array}$ \\
\hline
\end{tabular}

Many of the indigenous wood species are not available in large quantities or in suitable sizes for commercial exploitation as construction material. These special wood types are more expensive and used in furniture manufacturing or wood carving and parquet. It does not mean when wood products are not commercially available that they also technically cannot be used for building purposes.

Besides sawn wood (beams, planks, poles, slats), many different wood products are manufactured that find use in building applications. Laminated timber, multiplex and particle boards, fibre boards and wood polymer composites are used for production of various building elements (Table 2).

Table 2

Wood based products.

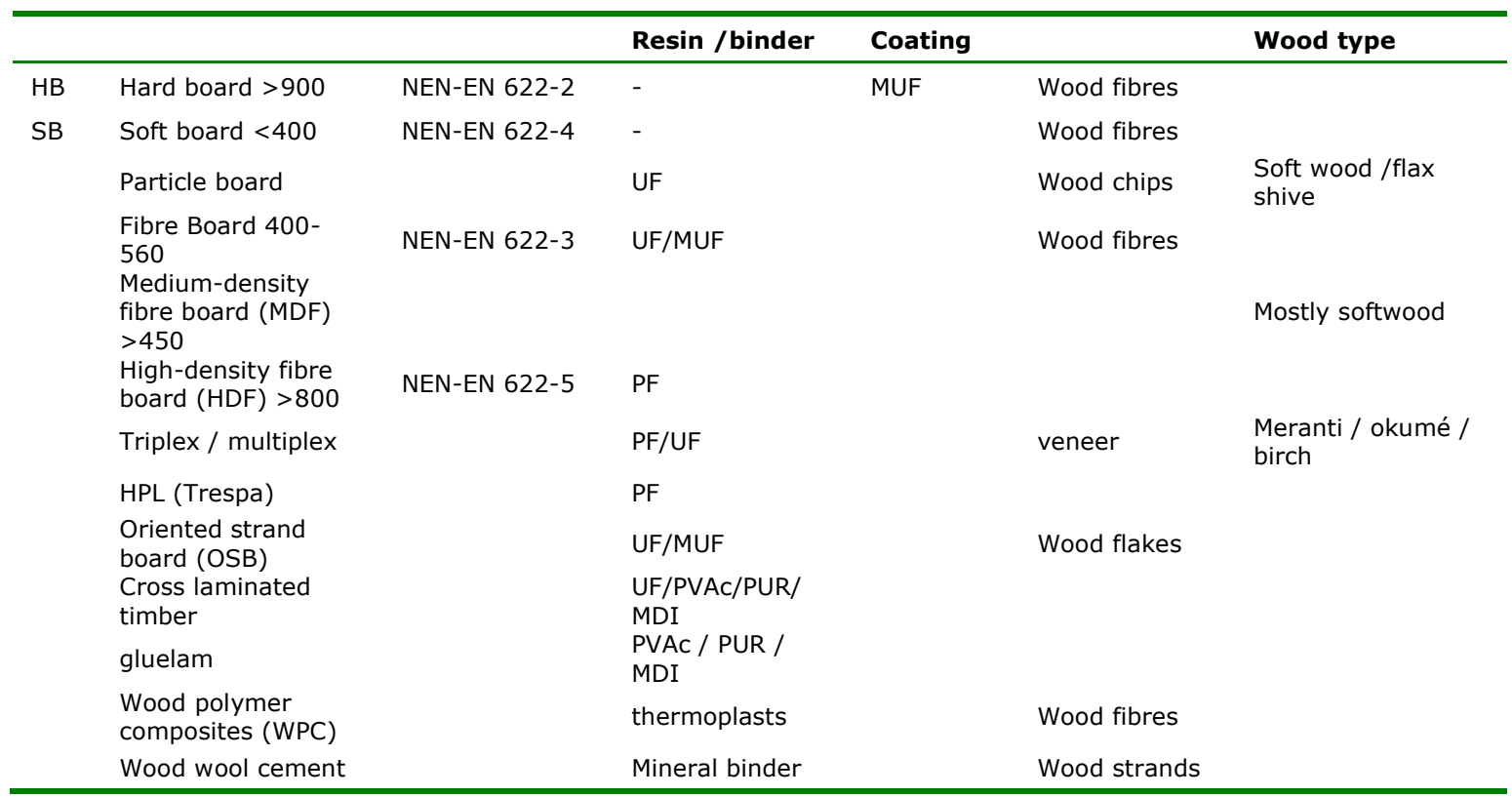

In the province of Gelderland a number of sawmills are active. Most of the timber they produce is used for outdoor applications, carports, fencing and partition. Only a small percentage of the locally grown logs is entering the regular building market. No industries have been identified in Gelderland that manufacture wood products such as particle board, fibre board, multiplex or veneers. There are manufacturers of end products such as doors, and prefabricated building elements. In Gelderland two companies are active that produce innovative modified wood products, which use common wood that is treated to enhance the durability. Accoya wood ${ }^{22}$ is chemically modified hydrophobized wood by acetylation reaction. Plato wood ${ }^{23}$ is using a thermal process that transfers the durability class of fir or poplar from 4 to 2 .

22 www.accoya.com/nl/

${ }^{23}$ www.platowood.nl/ 


\subsection{Different stakeholders along the value chain}

The transition towards a circular economy requires interplay between the quadruple helix partners: government, private sector, knowledge and civil society. Representatives of these domains need to be involved and engaged in order to realize the ambition of the Province of Gelderland and to arrive to implementation.

The project is focused to explore new value chains or circular loops in which local wood and wooden biomass (trees, timber) will be valorized into materials for the local construction sector. Within the value chain we can distinct the following links: biomass producers, timber processing, processors of building materials, retail and constructors. Within the different groups there is a large number and diversity of businesses, some large but many SME's, and many specific niches to distinct. Next to the production side of the construction market there is a demand side, which consists of private customers, local governments, housing associations and architects. Also we can distinct several intermediate organizations within the construction sector (Bouwend Nederland, interest group of Dutch construction sector) or organizations which play a role in the development and implementation of strategies and policies on circular and biobased economies and the acceleration of the implementation of the provincial program on climate change (Oost NL, KIEMT cluster, VNO/NCW, Economic Board Arnhem Nijmegen), or platforms and networks which are active within specific regions and areas within Gelderland (Cirkelregio Achterhoek, Cirkelstad Arnhem, Cirkelstad Nijmegen, CIRCLES, Circulaire Economie Arnhem Nijmegen, Bestuurskwartier Arnhem).

The Cirkelstad program ${ }^{24}$ in Arnhem, Nijmegen and the Achterhoek is an interesting novel initiative which may lead to valuable insights on what is needed to make better use of existing resources and to become more circular. In this program partners from all parts of construction sector such as housing associations, waste processing industries, architects, entrepreneurs, government, knowledge institutes and real estate companies collaborate.

To get a good impression of the possibilities and potential of a circular and biobased construction sector in Gelderland communication needs to be established with the different partners from different stakeholder categories: the representatives of the domains (government, private sector, knowledge institutes and civil society) and industrial actors along the value chain (biomass providers, processors, end product manufacturers, construction industry actors). The government (provincial and municipal) can be seen as initiator of housing projects and building assignments, but should also be approached as representative and guardian of public and societal values and as responsible for the implementation of policy objectives regarding climate change and economic development in balance with planetary boundaries. Also non-governmental organizations, for example the nature management organizations responsible for conservation of natural resources. The knowledge domain is represented by WUR (experts on technologies, economics, sustainability, forest and society), Probos, HAN (Higher Educational institute Arnhem-Nijmegen - on Circular economy) and KCPK (Kenniscentrum Papier en Karton).

A scheme of the subsequent links in the chain is provided in Figure 3.

\footnotetext{
${ }^{24}$ https://www.cirkelstad.nl/
} 


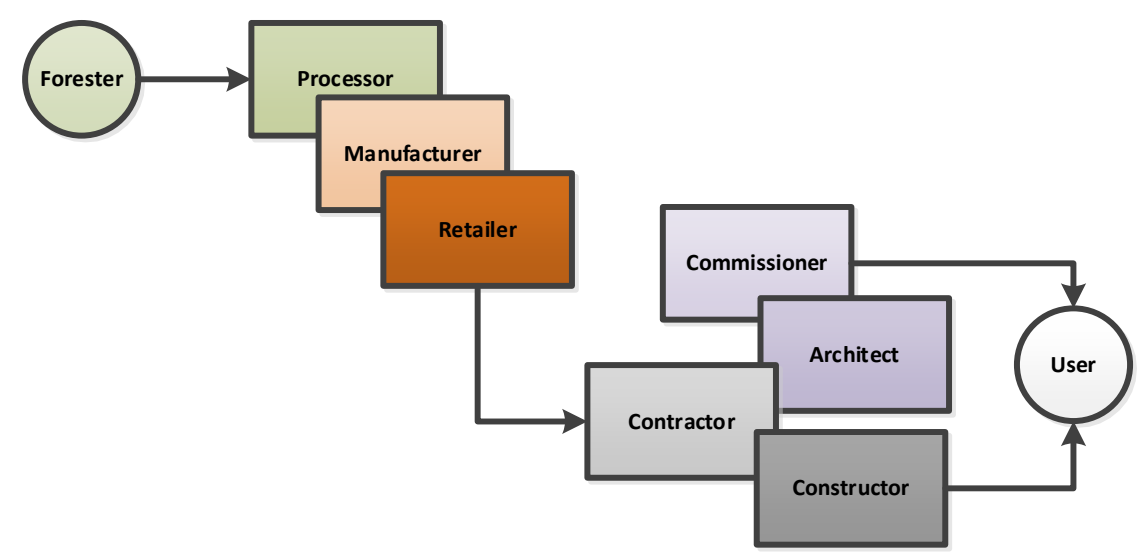

Figure $3 \quad$ Links in the wood based building chain

In this study, in order to get a good overview of current situation and experienced barriers we have conducted interviews with different stakeholder groups mentioned above including representatives from the province, the wood production and forestry sector (Staatsbosbeheer, Bosgroep, Midden Nederland, Probos, Centrum Hout), sawmills (Houtzagerij Holten, Edese Zagerij, Pluim), the building material producers (Timmerfabriek Neede, Accoya, Foreco, Platowood), the building material suppliers (Groenebouwmaterialen, Tulp-Bijl Hout, De Groot Vroomshoop, Raab Karcher), the constructors, contractors and architects (Orga Architecten). We have covered the whole value chain and the different domains (public, private, knowledge). Also we interviewed a representative from the initiative Cirkelstad De Achterhoek.

\subsection{Current availability of wood and use of local wood in the building industry}

The province of Gelderland is the most forested province of the Netherlands. The forest area of Gelderland covered 98.842 ha in 2019 , which accounts for $26 \%$ of the total forest area in the Netherlands [Probos rapport, Schelhaas et al. 2014]. ${ }^{25}$ Forests cover $20 \%$ of Gelderland's land surface. The most abundant species are Scots pine (Pinus sylvestris), common oak (Quercus robur) and Douglas fir (Pseudotsuga menziesii) (Figure 4).

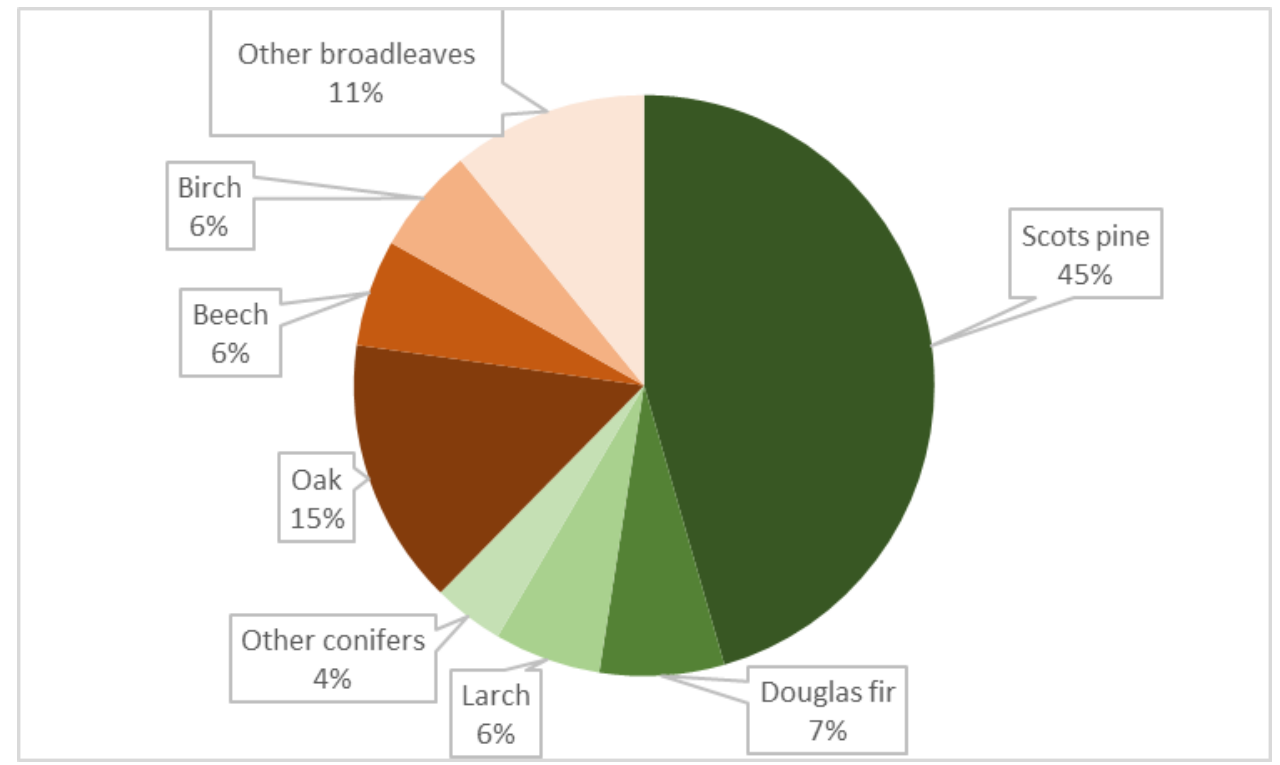

Figure 4 Distribution of area over tree species in Gelderland

${ }^{25}$ Schelhaas, M.J., Clerkx, A.P.P.M., Daamen, W.P., Oldenburger, J.F., Velema, G., Schnitger, P., Schoonderwoerd, H., Kramer, H., 2014. Zesde Nederlandse Bosinventarisatie; Methoden en basisresultaten. Alterra rapport 2545, Wageningen. 
The average wood volume (growing stock) in Gelderland's forests has increased considerably over the last two decades, from $205 \mathrm{~m}^{3} /$ ha in 2001-2005 to $243 \mathrm{~m}^{3} / \mathrm{ha}$ in 2019 . The total amount of wood standing in the forest in Gelderland is about 24 million $\mathrm{m}^{3}$ during the sixth National Forest Inventory (NFI-6, 2012-2013).

Figure 5 shows the age class distribution of Gelderland's forests during the sixth National Forest Inventory (NFI-6, 2012-2013). Most forests are between 40 and 120 years old. The relatively small area of forest younger than 20 years old indicates that only a small share of the forest has been regenerated over the last decades. The distribution of the growing stock over diameter classes shows a similar pattern (Figure 6). The majority of the wood volume is concentrated in the diameter classes 20-50 cm (Figure 6). These classes are dominated by conifers, while in lower and higher diameter classes broadleaves are relatively more frequent (Figure 7). The high share of birch and other broadleaves in the lowest diameter classes is a consequence of the general aim to promote an admixture of broadleaves in the forest. In the medium term, this may lead to drastic changes in the tree species composition of the forest, as conifers will be harvested since they are preferred by the industry, and are increasingly being replaced by broadleaves.

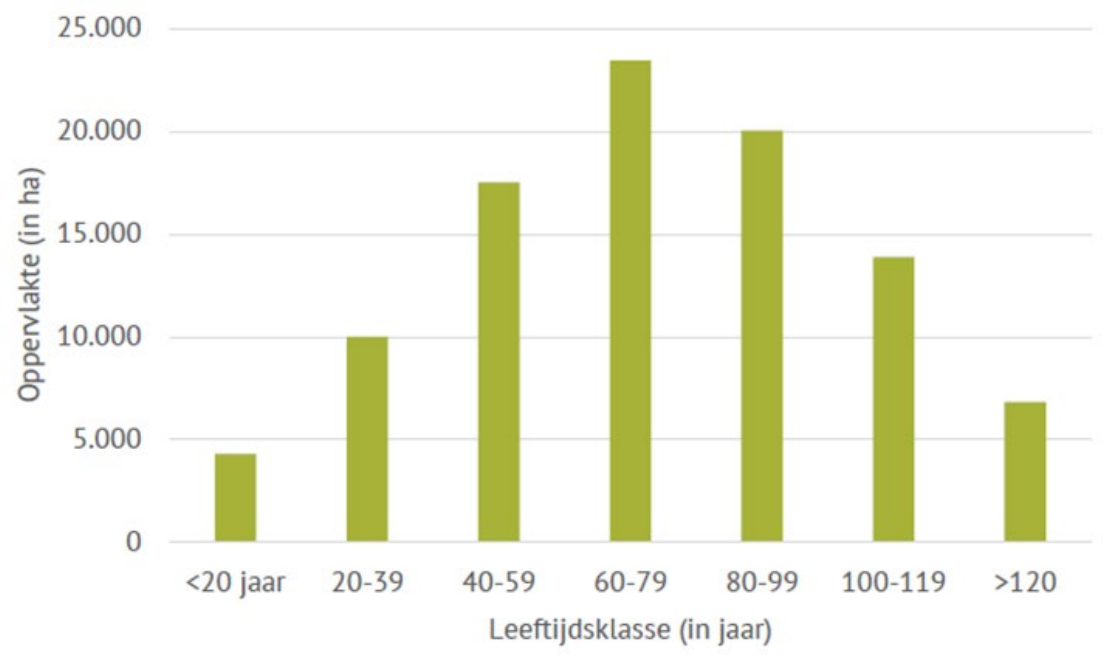

Figure $5 \quad$ Age class distribution of Gelderland's forests during the sixth National Forest Inventory (2012-2013)

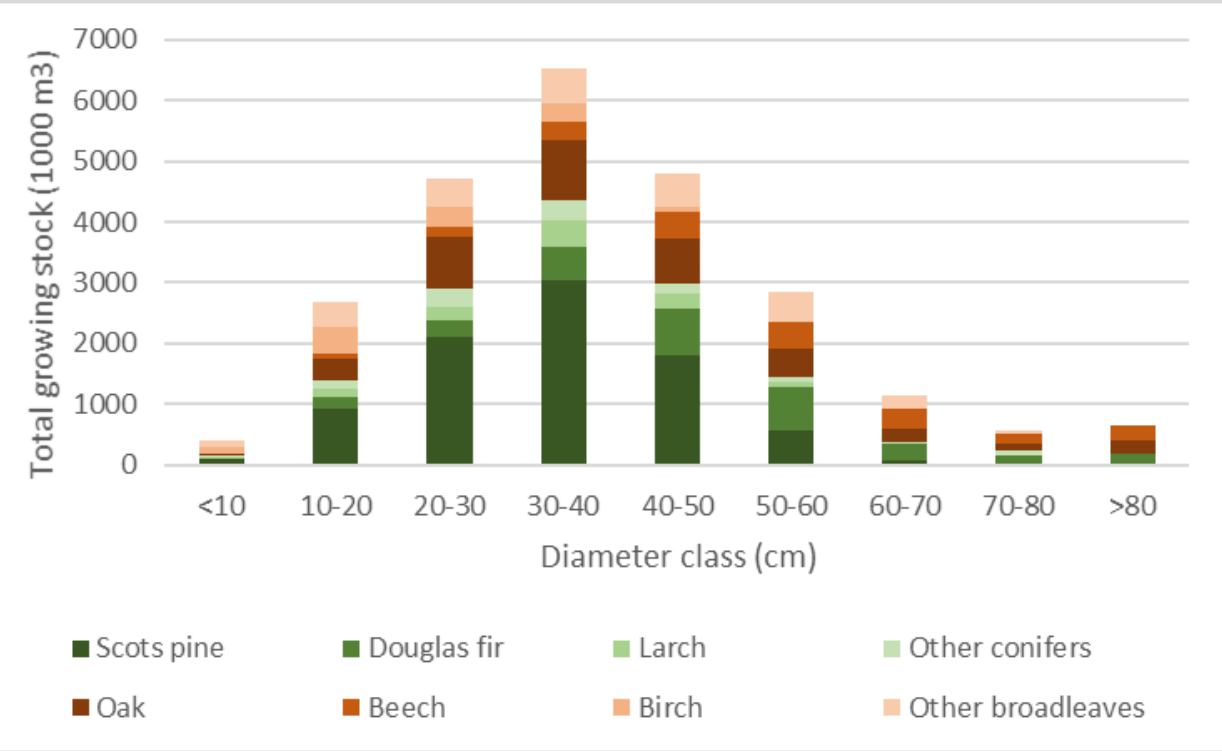

Figure 6 Absolute distribution total volume of wood over diameter classes per species in Gelderland during the sixth National Forest Inventory (2012-2013) 


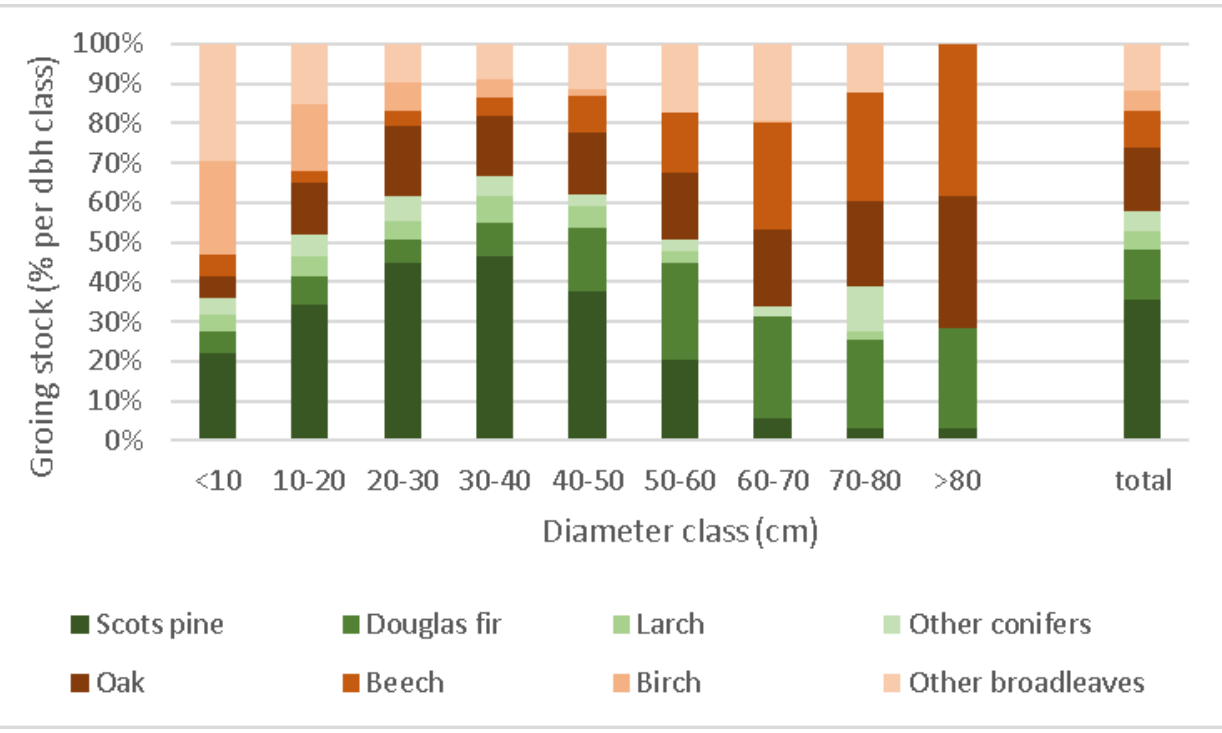

Figure $7 \quad$ Relative distribution of wood volume per diameter class per species in Gelderland during the sixth National Forest Inventory (2012-2013)

Both increment and felling volumes in Gelderland's forests decreased between fifth and seventh National Forest Inventory (NFI-5 and NFI-7). The increment rate decreased from $7.4 \mathrm{~m}^{3}$ per ha per year to $6.3 \mathrm{~m}^{3}$ per ha per year (Oldenburger 2020). ${ }^{26}$ The decrease in increment rate is mainly due to a change in tree species composition, with less focus on productive tree species. The felling rate decreased similarly from $4.4 \mathrm{~m}^{3}$ per ha per year to $3.6 \mathrm{~m}^{3}$ per ha per year. Between NFI-5 (20012005) and NFI-6 (2012-2013), the annual harvest is estimated to be in the range of 400,000 to $450,000 \mathrm{~m}^{3}$. An additional $11,500 \mathrm{~m}^{3}$ per year is estimated to become available due to the conversion of forest to other types of nature. Conifers are preferred by the industry, almost $80 \%$ of the harvested wood is coniferous (Figure 8). The distribution of the harvest over diameter classes (Figure 9) is similar to the current standing stock.

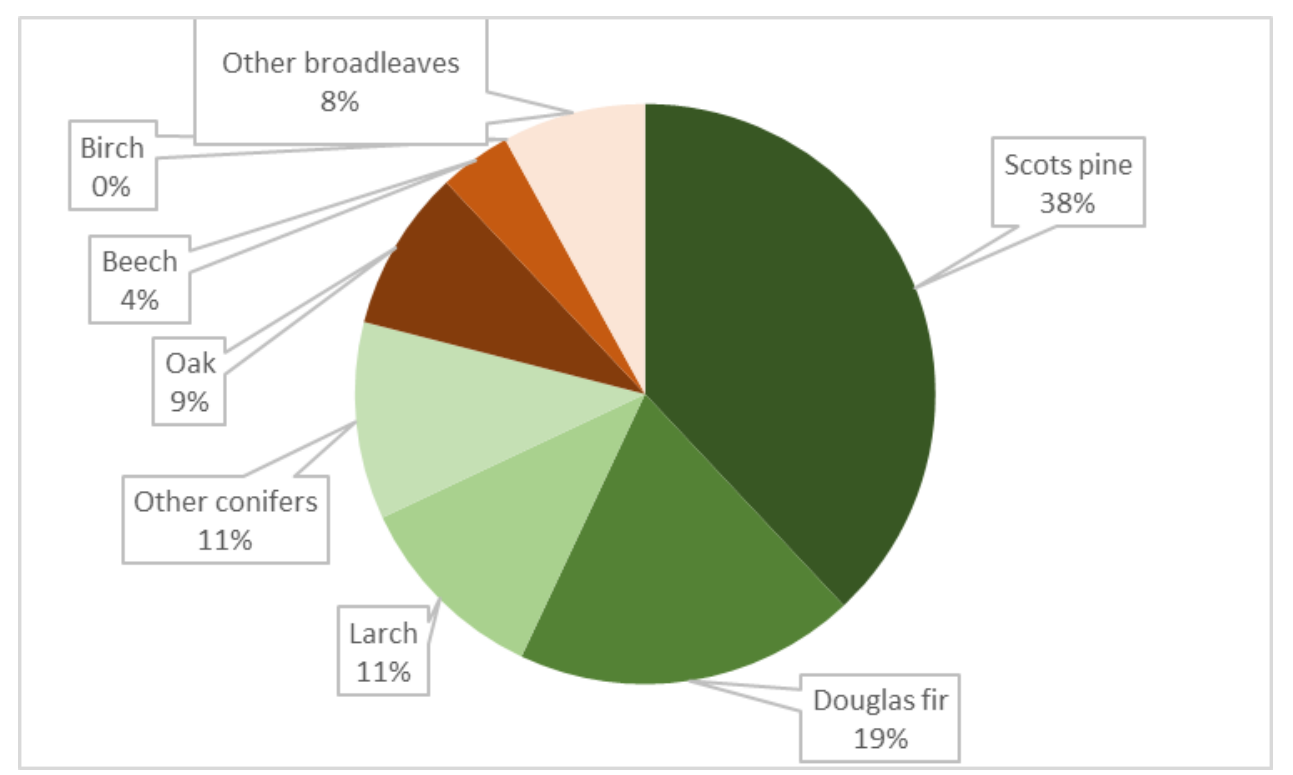

Figure 8 Distribution of harvest over species over the period 2001-2019

\footnotetext{
${ }^{26}$ Oldenburger J, Teeuwen S, Kleine C de, Schoonderwoerd H, Spliethof N, Borgman D, 2020. Stand van zaken van het bos in Gelderland - Feiten en cijfers. Leveren van inzicht ter ondersteuning van de ontwikkeling van een provinciale bosvisie. Probos, Wageningen.
} 


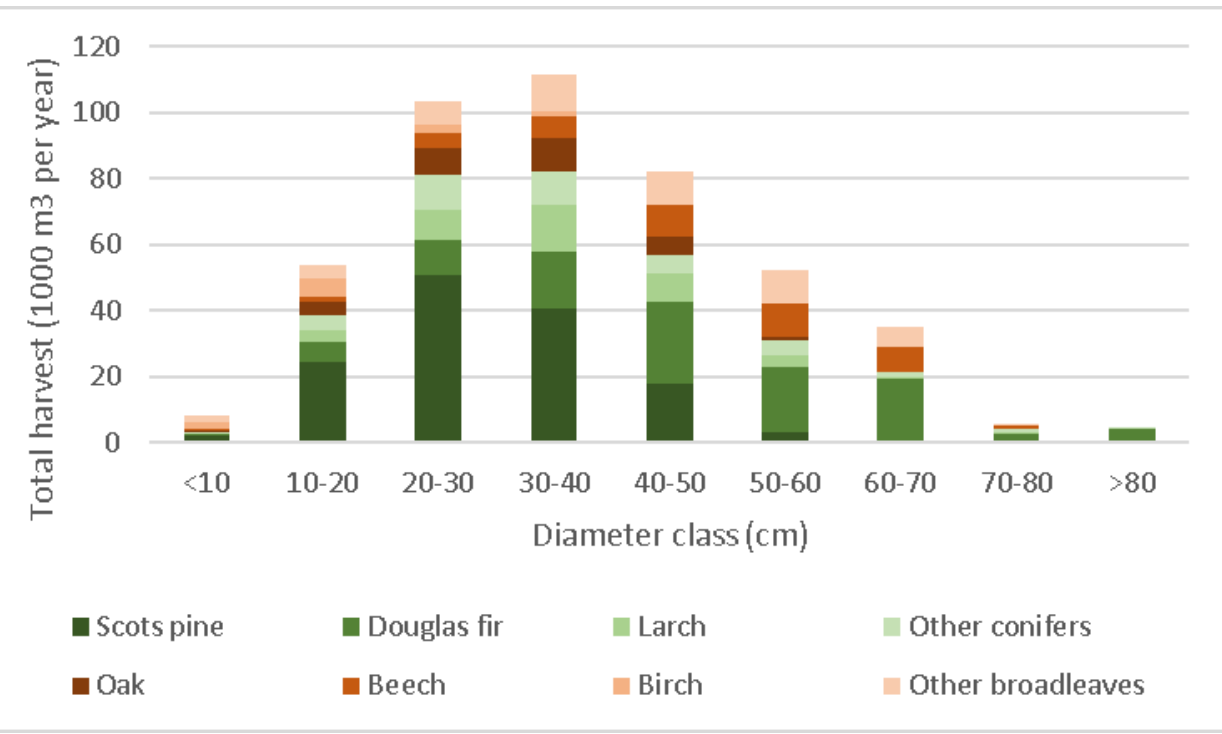

Figure 9 Distribution of harvest over species and dbh classes as estimated over the period 2013-2018

Table 3 shows an estimation of the flows of the roundwood harvest from regular forest management to different types of wood products. Almost $80 \%$ of the roundwood harvest volume is directed to industrial roundwood, while $20 \%$ is used as firewood. No roundwood is used directly as biomass for bio-energy. No information is available on how much of the harvested wood is used within the province and how much is exported. For the Netherlands as a whole, Nabuurs et al. (2016) ${ }^{27}$ estimated that $54 \%$ of the industrial roundwood was processed nationally, while $46 \%$ was exported. An important reason for export is the lack of a panel board industry in the Netherlands, which is an important buyer for the pulpwood assortment, consisting of lower quality and smaller dimensions.

Table 3

Estimation of flows of roundwood harvest volumes to different types of wood Products

\begin{tabular}{ll}
\hline Type & $\begin{array}{l}\text { Percentage of roundwood } \\
\text { harvest }\end{array}$ \\
\hline Industrial roundwood & $79.9 \%$ \\
Sawn timber & $40.1 \%$ \\
Pulpwood & $35.9 \%$ \\
Other industrial roundwood & $3.9 \%$ \\
Firewood & $20.1 \%$ \\
Biomass for bio-energy & $0.0 \%$ \\
Total & $100 \%$ \\
\hline
\end{tabular}

\footnotetext{
${ }^{27}$ Nabuurs GJ, Schelhaas MJ, Oldenburger J, de Jong A, Schrijver R, Woltjer G, Silvis H, 2016. Nederlands bosbeheer en bos- en houtsector in de bio-economie. Scenario's tot 2030 in een internationaal bio-economie perspectief. Wageningen Environmental Research rapport 2747.
} 


\section{Defining the potential of biobased building materials for improved sustainability and circularity in Gelderland}

\subsection{Enabling and restricting framework, governance and policy for biobased building materials}

The description of the policies at European, National and provincial level may lead to the conclusion that the strategic frameworks are available, are aligned on the different levels and are completed. The challenge now is to bring the missions into practice, to realize the circular bio-economy, and to create and implement new perspectives for regional economies in balance with the planetary boundaries. Europe has been leading in ambitious strategies and programs on bio-economy. Europe has developed large knowledge and innovation programs to invest in expert knowledge on technologies on the potential of various forms of biomass and the valorisation in different kind of production lines. The Bio-economy Stakeholder Panel, consisting of stakeholders from universities, industries, civil society and regions, have concluded that more attention should be given at putting the expertise in practice, bring the ideas and pilots further into full scale investments and to reach out for the civil society (Bioeconomy Stakeholder Panel, 2017) ${ }^{28}$. Regions have determined their Research and Innovation Strategies for Smart Specialization (RIS3) and have developed triple or quadruple helix approaches. Regional partners are being challenged to develop innovative solutions for the regional missions, as climate change and developing a circular economy.

\subsubsection{EU level}

The Green Deal (2019) ${ }^{29}$ is an integral part of this Commission's strategy to implement the United Nation's 2030 Agenda and the sustainable development goals (Climate, biodiversity loss). The European Green Deal is a response to climate and environmental-related challenges. It is a new growth strategy that aims to transform the EU into a fair and prosperous society, with a modern, resource-efficient and competitive economy where there are no net emissions of greenhouse gases in 2050 and where economic growth is decoupled from resource use via circular use of feedstocks. The European Green Deal will be a driver of new economic opportunities. Many European firms are cutting their carbon footprint and discovering cleaner technologies. They understand that there are planetary boundaries. They also know that if they discover the sustainable solutions of tomorrow, this will give them first mover advantage.

The European Commission (EC) has adopted a new Circular Economy Action Plan ${ }^{30}$ (2018) - one of the main blocks of the European Green Deal, Europe's new agenda for sustainable growth. The new Action Plan announces initiatives along the entire life cycle of products, targeting for example their design, promoting circular economy processes, fostering sustainable consumption, and aiming to ensure that the resources used are kept in the EU economy for as long as possible. The Action Plan focuses in particular on resource-intensive sectors such as textiles, construction, electronics and plastics. Promoting new forms of collaboration with industry and investments in strategic value chains are essential.

Achieving a climate neutral and circular economy requires the full mobilization of industry. It takes 25 years - a generation - to transform an industrial sector and all the value chains. ${ }^{29}$

\footnotetext{
${ }^{28}$ Bioeconomy Stakeholder Panel, 2017; Manifesto. Brussel

${ }^{29}$ European Commission COM(2019) 640. The European Green Deal. Brussel.

${ }^{30}$ https://ec.europa.eu/environment/circular-economy/pdf/new_circular_economy_action_plan.pdf
} 
In synergy with Green Deal and Circular Economy Action Plan, a Sustainable Product Policy is in development to support the circular design of all products based on a common methodology and principles. This policy will prioritise reducing and reusing materials before recycling them. It will foster new business models and set minimum sustainability requirements to prevent environmentally harmful products from being placed on the EU market.

A just transition framework for the circular economy can facilitate identifying opportunities that reduce resource consumption and waste generation, stimulate product innovation, and contribute positively to social wellbeing. The circular economy concept as a central component in local and regional economies, will support creating sustainable circular ecosystems and designing community-based participatory schemes. An increasing number of cities, regions, industries and businesses are engaged in testing and improving circularity in their territories, economic sectors, value chains and services. Nevertheless, the concrete implementation of systemic solutions for the territorial deployment of the circular economy still needs to be demonstrated.

The 2018 update of the Bioeconomy Strategy ${ }^{31}$ aims to accelerate the deployment of a sustainable European bioeconomy based on three key priorities:

1. Strengthen and scale up the bio-based sectors, unlock investments and markets

2. Deploy local bioeconomies rapidly across the whole of Europe

3. Understand the ecological boundaries of the bioeconomy

Regarding the regional bio economies, EC favours a systemic approach, which will address bio-based innovations including in farming, to develop new chemicals, products, processes and value chains for bio-based-markets in rural areas, with involvement and increased benefits for primary producers. And, new opportunities arising for the forestry sector in view of replacing non-sustainable raw materials in construction, packaging with bio-based materials and for providing more sustainable innovations in sectors such as forestry-based textiles, furniture and chemicals, and new business models based on the valuation of forestry ecosystem services.

The EC gives directions towards the developments, based on insights gained from research programmes and projects, advice received from experts and consultants, and from exchange on various panels and conferences. The EC aligns the different strategies and regulations among the different Directorates-General (DGs), which are responsible for different policy areas. DGs develop, implement and manage EU policy, law, and funding programmes. EC asks Member States to align also their national strategies and policies. The regional level is a suitable scale for applying integrated approach of socio-economic, environmental and technological innovations, as well as mobilising different relevant quadruple helix partners. EC offers funding for regions to implement their strategies supporting new biobased value chain and new business development.

\subsubsection{National policies}

The main national frameworks for the biobased and the circular economy are National Climate Agreement $^{32}$ and the Circular Economy Plan by $2050(2016)^{33}$. The last periods there still was demand for using biomass as a renewable energy source as a transition fuel. Currently ${ }^{34}$ it is decided to stop this practice and to optimize the use for higher applications of valorization. The national government is aiming at increasing the supply of sustainable biomass as much as possible. An adequate food supply and preservation of soil fertility and quality, water and air, are important preconditions for the development of the biobased economy. In addition to increasing the sustainable supply of biomass, major challenges are the improvement of conversion techniques and the change of market demand to give biobased raw materials preference over 'fossil' feedstock.

\footnotetext{
${ }^{31}$ European Commission (2018). A new bioeconomy strategy for a sustainable Europe. Brussel.

${ }^{32}$ Government of the Netherlands (2019). Climate Agreement. The Hague.

${ }^{33}$ Government of the Netherlands (2016). A Circular Economy in the Netherlands by 2050. https://www.government.nl/documents/policy-notes/2016/09/14/a-circular-economy-in-the-netherlands-by-2050

${ }^{34}$ Coalition Agreement Dutch Government; 15122021
} 
The Biomassa $2030(2015)^{35}$ policy framework has a focus on valorisation of biomass. It considers enlarging the production of biomass including aquatic biomass and to improve the collection of rest streams towards new commodities. Moreover, to optimize the utilization of biomass and its components, and to discover new applications of biomass in a broad pallet of biochemicals and biopolymers. Furthermore to invest in new production capacity, in research and development and in new technologies: first of a kind production plants and bio-refineries.

The Circular Economy Plan by 2050 (2016) has a focus on reducing primary raw material use, reducing imports, replacing fossil resources with renewable sources. Construction is one of the main sectors $(2018)^{36}$. Relevant actions are:

- All public procurement based on circular economy

- Reduction of $\mathrm{CO} 2$ emissions in construction

- Decision about Materials passport for buildings

- Subsidy for development of circular business models

- Monitoring and measurement of circularity

- Circular building will be integrated in Educational programs

- Knowledge institute for circular building awareness raising

Relevant for the use of wood for construction is the new Bossenstrategie (2020) ${ }^{37}$, as part of the National Climate Agreement. The objective is to focus on planting 37000 ha with forest in order to increase the capture of $\mathrm{CO}_{2}$, in combination with biodiversity objectives and raising production of renewable resources for high value biobased products, for example for use of wood in construction sector.

The Dutch Minister of Agriculture, Nature and Food (LNV) is exploring the concept of Circular Farming $(2018)^{38}$. This is taking place at demonstration farms, within research programs and by bringing together all kinds of experts at conferences. Relevant for the increase of biobased production within this concept is the initiative of the Ministry of LNV to assess possibilities to increase the biomass production in the Netherlands, based on potential of different landscape and soil characteristics. Focus is on arable farming (sugar beets) and lignocellulosic biomass (wood, Miscanthus, other grasses). This is also relevant for Gelderland to investigate where to produce lignocellulosic biomass such as Miscanthus, how to increase the wood production and what role is foreseen for agricultural sector.

\subsubsection{Province of Gelderland}

From the European Regional Development Fund (ERDF), EU regions are challenged to make strategic choices to invest in specific sectors or challenges, which fits to the characteristics and qualities of their economies and environment and compared to other regions (Regional Innovation Strategy Smart Specialization, RIS3). Many regions have mentioned the bio-economy as one of the main drivers for regional innovation and growth. Within the bio-economy many routes are possible, depending on the combination of availability and components of the regional biomass and the existing industries for valorisation.

In the RIS3 (2014-2020) ${ }^{39}$ the strengths of East Netherlands are described as following: knowledge areas such as microbiology, sustainable and green chemistry, life cycle analysis, ecology, biobased materials \& products and more specifically from research into pyrolysis and biomass, leading to new chains and techniques for a more sustainable economy (circular economy).

\footnotetext{
35 Ministerie van Economische Zaken en Klimaat (2015). Biomassa 2030. Strategische visie voor de inzet van biomassa op weg naar 2030. https://www.rijksoverheid.nl/documenten/rapporten/2015/12/01/biomassa-2030

${ }^{36}$ Transitieagenda Circulaire Bouweconomie, (2018-2023)

${ }^{37}$ Ministerie van LNV (2020). Nieuwe Bossenstrategie en beleidsagenda 2030. https://www.rijksoverheid.nl/documenten/kamerstukken/2020/11/18/uitwerking-ambities-en-doelen-landelijkebossenstrategie-en-beleidsagenda-2030

${ }^{38}$ Ministerie van Landbouw, Natuur en Voedselkwaliteit (2018); Visie Landbouw, Natuur en Voedsel: Waardevol en Verbonden. https://www.rijksoverheid.nl/ministeries/ministerie-van-landbouw-natuur-envoedselkwaliteit/documenten/beleidsnota-s/2018/09/08/visie-landbouw-natuur-en-voedsel-waardevol-en-verbonden

${ }^{39}$ OP Oost (2013). Operationeel Programma EFRO 2014 - 2020 Oost-Nederland.
} 
The province of Gelderland clearly focused on three bioeconomy routes as drivers for regional innovation and growth: valorisation of manure, vegetable proteins and lignocellulose. Being the countries most wooded province and hosting a significant paper mill industry, innovations in fibre applications of wood and fibre-rich crops and residues are a logical and very promising choice. Elements for implementation were: growing natural fibres (wood, hemp, Miscanthus), pilot industrial site, biorefineries, waste collection, cluster approach.

In the new RIS4 2021-2027 (2020) ${ }^{40}$, there is no focus anymore at Biobased Economy or Circular Economy. It is a frame that supports companies in food(tech), materials(tech) and health (medtech) to innovate and grow. Connection with the regional physical characteristics concerning available bioand waste resources, which are key to develop the circular bio economy, are missing. As Green Deal in Europe is seen as the new growth strategy, this seems mainly relevant for the energy objectives in Gelderland. In the new RIS4 document there are no directions towards innovation sustainable smart specialization, greening the economy and the circular economy. This framework does not offer direct and focussed support for the development of a circular economy.

Gelderland with the Circular Action Agenda $(2016)^{41}$ is aiming at supporting circular initiatives, pilots and awareness raising with the following tracks:

1. Province as launching customer: circular buying strategy

2. Smart industries: awareness raising, reduction and recycling of waste

3. New biobased resources: natural fibres (hemp and grasses), extraction of nutrients from manure and transition towards green proteins.

At the innovation track for natural fibres different new regional value chains between crops and industries have been explored, with much focus at the sustainable application in paper and textile industry. Kiemt Cluster foundation is supporting this development.

In 2019, the political agreement 'Together for Gelderland' focused on Implementation of the Circular Economy Implementation Agenda (2020 ${ }^{42}$. The provincial coalition further invested in the circular economy, as part of the food and energy transition, with a focus on using waste as resources, limit imports of resources (by 50\%) and use the current resources in the province as optimal as possible.

Province of Gelderland wants to support initiatives which have the objective to scale-up. Based on the Circular Atlas (2019) ${ }^{43}$, the province of Gelderland considers three options:

- Decrease of use of primary or virgin resources and materials

- Re-use of resources and materials in closed circles

- Replace primary and finite resources by biomass and biobased resources

Compared to the Circular Action Agenda (2016) on circular economy, in the Implementation Agenda (2020) Gelderland focuses more on value chains instead of individual business cases; every initiative should have two or more partners working together in the value chain. Efforts must increasingly shift to the actual reduction of raw materials consumption, stimulating market demand, application and realization. This is increasingly possible because economically profitable bio-based and circular business cases emerge.

\footnotetext{
${ }^{40}$ Op Oost (2020). Slimme specialisatiestrategie (RIS3) Oost-Nederland 2021-2027. https://www.opoost.eu/bestanden/Documenten/OP-Oost/2021-2027/RIS3_Oost-Nederland_versie_1_0_DEF.pdf

${ }^{41}$ Provincie Gelderland (2016) Uitvoeringsagenda Circulaire Economie https://gelderland.stateninformatie.nl/document/4722051/1/Uitvoeringsagenda_

42 Provincie Gelderland (2019). Van ketens naar kringlopen Uitvoeringsprogramma Circulaire Economie 2021 - 2023. https://www.gelderland.nl/bestanden/Gelderland/Nieuws-enevenementen/DOC_Uitvoeringsprogramma_Circulaire\%20Ecomomie.pdf

43 Provincie Gelderland, Royal Haskoning DHV (2019). Circulaire Atlas Gelderland. https://www.gelderland.nl/bestanden/Documenten/Gelderland/06Werk-enondernemen/191125_Circulaire_Atlas_Gelderland.pdf
} 
The province wants to achieve this by the multi-output valorization of biomass (using all the fractions of biomass, sales in various sectors) and in this way formulate a solid business case. Policy objective regarding biomass availability and application in Gelderland concerns where in Gelderland, what type, in which quantities and for which applications, extra biomass can be made available as raw material for new protein-rich food, regionally grown animal feed, for the industry (e.g. construction, paper, textile). This calls for an implementation-focused, action plan together with (potential) producers of biomass, processors and market parties to investigate whether a (provincial) incentive instrument can be created to open up the market for specific biomass applications to replace finite, fossil raw materials.

In the implementation agenda (2020), the province is searching for value chain projects in four categories ('tiles"): agrofood, building and construction, consumer waste and manufacturing industry. These sectors consume the largest volumes of resources, and they are challenged to come with project proposals, in order to realize a decrease of $50 \% \mathrm{CO}_{2}$ in primary resources. The program on building and construction is focused on recycling and the use of biobased materials, for example based on wood, hemp, flax, reed and Miscanthus. The other sub goals are flexible building formulas and new functions for existing buildings. The program focuses on the resources, the building materials and the construction sector. The province is looking for projects and initiatives underneath the different programs by contributing in the following way: as a buyer of circular products and with their provincial environmental services organizations ("Omgevingsdiensten"), as a policy maker, as a supporter with their innovation ecosystem partners (Oost NL, KIEMt cluster, Circles program), with financial means for innovation (ERDF). The province is working at a regulation for material use in new housing programs.

At the national level the Forest Strategy (Bossenstrategie, 2020) has been introduced, with an objective to increase the amount of forest by $10 \%$. To implement this strategy at the provincial level, since 2020 Gelderland has been working at an Implementation program for Trees and Forest ${ }^{44}$, together with the nature management organizations. It is important to have a good overview on current state of forests as well as the potential locations and strategies to extend the volumes in Gelderland. The Implementation program is focusing on more vital and diverse forest, and on increasing the amount of trees in the rural and urban areas. This concerns enhancing the qualities of the forest, increasing biodiversity, mitigation of GHG emissions by capturing and storing carbon in trees, as well on climate adaptation and decreasing heat stress in urban areas. Use for biobased applications is only implicitly mentioned by increasing agroforestry in rural areas, which can lead to biomass production for the fibre valorization activities in Gelderland.

\subsubsection{Reflection on policies and strategic choices}

A shift is seen from biobased economy towards a circular bioeconomy, which is also the case in Gelderland. Relevant policy frames are available at all levels and concern climate, circular bioeconomy and regional growth strategies, but are not perfectly in line with each other. There are also differences in interpretations. As the European Green Deal is seen as a Growth Strategy, and as the concept of RIS3 (regional innovation strategy of smart specialization and the operational program for Easter Netherlands) is moving towards RIS4 (regional innovation strategy of sustainable smart specialization), it seems that Eastern Netherlands (Gelderland and Overijssel) is choosing for the pragmatic way. Policies on biobased valorisation seems to have less attention than in the former RIS programming period (2014-2021). This is not supportive for biobased innovations, as they take time and need long term support and strategic decision making.

With the Circular Economy Action Agenda (2019) and the Gelderland Atlas (2019), there is foremost attention to decrease the use of resources (imports) and to reduce and valorise waste. The attention to produce biomass is relevant for the development of sustainable products in regional value chains based on renewable resources, and for the deployment of the bioeconomy and for the regional circular economy.

\footnotetext{
${ }^{44}$ Vitaal en divers bos; uitvoeringsprogramma bomen en bos; provincie Gelderland, 15 december 2020.
} 
So, in summary, what is available for the regional wood valorization for construction sector?

- At all levels frameworks are set for combatting climate change, decrease of GHG emission, and for stimulating circular bio economy.

- Regional Operational Program, to be seen as the growth and development strategy, has no specific focus on innovations in bioeconomy.

- But there is a provincial Circular Action Plan, with a focus on Construction sector and with funding for piloting and testing projects.

- There is attention for value chain approach, but implementation schemes and support is limited.

- Wood production for materials is very limited in the province - more attention for increase of local wood production and allocation for material use in Gelderland is needed.

- The existing frameworks and instruments give only limited support for enabling regional wood value chain development for applications in construction sector.

\subsection{Hurdles faced by biobased building materials in the market}

\subsubsection{Approach}

To identify the current hurdles and potential for biobased building materials in the local building industries in Gelderland, several representative stakeholders in Gelderland (and some adjacent areas), active in wood production, processing and use were asked questions about current use and sources of wood in construction applications and the options for sourcing of local wood.

\subsubsection{Outcome of stakeholder interviews}

Commissioners who are ecological aware and wish to use local wood in their building project are facing problems in acquiring the proper raw materials. The supply of the right volume of timber of the proper dimensions was difficult and some products needed production from roundwood and caused significant delay of the building process. Local timber wood was more expensive due to scarcity and small-scale operation.

The architects designing "green" or ecological constructions, like wood frame buildings, are dependent for the choice of building materials on the executive parties (project developers, contractors, constructors), who calculate significant surcharge on innovative wood building projects. This often makes the costs too high and shift the choice to regular building materials. Other aspects are the building regulations (e.g. vapor barrier, fire safety) that hinder the use of wood and biobased materials in building projects or artificial installations need to be used for mechanical ventilation to reach the indoor climate targets for buildings like required for conventional (fossil) non-breathing materials. A big ecological advantage of pre-fab wood products is their relative low density, which is favourable regarding less fuel use and nitrous (NOx) emissions for transportation. Wood based building projects do get easier permit now because of this.

Carpentry factories are currently importing most (more than 95\%) of their wood from Scandinavia or Eastern Europe. FSC certification of wood is important and is becoming more expensive due to the high demand. The wish to acquire wood more locally exists and options for $\mathrm{CO}_{2}$ compensation by planting new trees are of interest. Extension of the commercial forest plots in Gelderland would be welcomed. Important is the quality of the timber. Modified wood of fast-growing species (Accoya, Plato, Finti, etc.) is used more frequently. There is an increased demand for engineered wood products such as cross-laminated timber (CLT), glued laminated timber (gluelam), etc.

Companies that produce modified wood products for building in Gelderland are Plato BV and Accys BV in Arnhem. Both modify fast growing wood (Spruce, Pine, Poplar) by, respectively, thermal or chemical treatments. All raw material is now imported because local supply is of lower quality and not suitable for the process. Also Nobel wood (Foreco BV, Denekamp) is a modified wood product that finds application in outdoor uses such as facade cladding, roof mouldings, etc. 
Foresters produce local round wood that is now largely transported to Germany for large scale processing in sawmills. There is no local infrastructure for manufacturing fibre boards, particle boards, etc. Local sawmills process regional wood that finds mostly use as garden wood, fences, carports, etc. Local wood is more expensive due to the relative high labour costs involved and does not enter the construction market retail. Most in demand is Douglas, but that is considered to be an invasive species and production in local forests is not promoted which is also the case for Robinia. Larix is in demand as timber wood.

Local wood use is difficult because of subsidised bioenergy plants. More than $75 \%$ of the harvested wood in The Netherlands is used as fuelwood ${ }^{45}$. It will be difficult to enlarge production scale because of poor forest management. The forests are not managed for timber production. Logistics are a major problem as there are many small forest owners and there is no commercial forestry. Lack of stock of qualified logs and planning of supplies to the building sector hinders entering the market, even when demand is increasing.

But there is also a positive storyline. The forest sector partners that were interviewed are all actively exploring to valorise wood in a more sustainable manner than the use for green energy and are all actively building new relationships and projects in which new value chains are being developed. There is attention for valorising different wood species and qualities, but also for the different parts of a tree all with their specific opportunities for valorization in materials. Important conditions will be standardization of tree species, systems and sizes for application in the market. And for Gelderland to find their position, niches and specializations. This requires collaboration among partners along the value chain.

These partners are also seeking for the appropriate scale to organize the whole value chain of wood production, sewing and processing facilities. It is the question if this is feasible within Gelderland, as scale is needed for meeting the production volumes, but also the logistics for collection of resources is important. Conclusion is that Gelderland as a region distinguishes itself on wood production, institutional attention, knowledge base and network organizations. These are strong aspects to play a key role in building the value chain from wood to construction. But the optimal scale seems to be somewhat larger than the province. Collaboration with other provinces, even cross border with Germany is recommended. And connecting the value chain partners (private sector) will be another condition to meet.

Next to this, we have explored the practice of Circle Region Initiative in the Achterhoek, in which Achterhoek partners from construction sector have started to explore what is needed to make the sector and the region more circular. There are different subjects on their agenda, such as starting to store all data on materials used during construction of houses in order to be able to reuse all elements after lifetime. Also the region started to re-use waste from buildings and houses in the region. Re-use of materials from current houses and buildings faces a lot of problems, as it is often not possible to divide the waste into valuable new resources, as paint should be removed from wood for example. Therefore the partners are focusing on the development of flexible building materials and panels, to be able to build and rebuild easily for specific demand and changes in demand within the region. The circle region partners are working on public procurement and agreements on circular building for large building programs and "housing corporations". The circle region network has formed a Community of Practice in which different aspects of the transition towards circularity are being discussed. Also the Circle region wants to show what's already possible. The initiator has built a circular office and established showcases of the flexible housing program. It would help when more pilots would be established. It is important to develop showcases and storylines in order to reach out to the value chain partners to illustrate the need and perspectives of circularity, to create awareness and to change common practices.

\footnotetext{
${ }^{45}$ https://ec.europa.eu/eurostat/statistics-explained/index.php/Wood_products_-_production_and_trade
} 


\section{Recommendations}

To overcome the observed hurdles for using local wood in building and construction it is recommended that the planning and logistics of supply is better organized. This requires commercial wood management and organization of the trade. Essential is that information on stock of suitable timber for the market is available for potential users. Centralized distribution of locally produced (certified) sawn wood and a building market web-shop for quality graded timber will facilitate the commercialization. Support for branding of local produce and a premium for lower $\mathrm{CO}_{2}$ emission (less transportation distance) in a building project could promote wood from Gelderland for construction. The use of wood in bioenergy plants should be discouraged and the subsidy on fuel wood use reduced.

There is a lack in the Netherlands of companies that manufacture panels and boards. The commercial production of fibre boards requires supplies of large volumes of wood /wood chips, which the local forests cannot supply. Only half of the annual harvest goes to industry, the rest is fuelwood. The cost of logistics also hinder the supply. No summer harvesting is allowed in the Netherlands which creates for a panel and board company insecurity of a stable supply. Also local smaller scale operations cannot compete with the panel and board industries in other regions in Europe, as long as the costs and environmental impacts of transport do not have significant effect.

Companies that manufacture modified wood products are well represented in the province. The demand for wood products with higher performance such as Accoya, Platowood, Nobelwood, Thermowood etc. in building applications is expected to increase. The expansion potential for using local wood in their production should be investigated.

The abundantly available wood species (oak, beech, poplar etc.), which currently are underutilized in construction, because of availability, price or workability, could be promoted in certain selected uses.

\subsection{3 'Green' building market development}

It is expected that in the near future the share of fuel wood will decline, while the demand for industrial roundwood will grow ${ }^{46}$. The potential is recognized of wood use in construction for avoidance of $\mathrm{CO}_{2}$ emission, when applied sustainably. The EU policy on green building is aiming at energy and resource efficiency to help fight climate change ${ }^{47}$.

The limited and slow market penetration of biobased construction products is partly caused by the current large-scale construction methods, which are very competitive and save as much as possible on material costs and labour. A new competing product must be both cheaper to build and easier to install. Experimental products cannot compete and are considered of higher risk for the constructor, who has no incentive to use more wood. Many of the alternative biobased products are not (yet) registered in the NMD (National Milieu Database) and therefore far less likely a product of choice in a building project.

Most sawnwood used for building applications is softwood timber. The market growth for solid timber is expected to be modest while the use of engineered wood products (CLT, glulam) and panels (Plywood, HDF, MDF, OSB) are expected to grow significantly.

Wood and wood products are sensitive to biodegradation if the moisture content becomes too high ( $>$ approx. 20\%), which means that measures are necessary, especially for outdoor applications, to prevent premature degradation. In addition, exposure to weather influences such as UV light, rainfall and temperature variations also have a negative effect on the material properties. To protect wood and wood products against moisture, UV light or attack by micro-organisms (fungi), a water-repellent, impermeable layer is often applied. Alternatively, chemically of thermally modified wood products are entering the market. Regular maintenance of wood constructions, especially in outdoor applications is important for the functional durability.

\footnotetext{
${ }^{46}$ https://www.unece.org/fileadmin/DAM/timber/publications/FPAMR2018.pdf

${ }^{47}$ European Council. 2018. Energy efficient buildings: Council adopts revised directive. Available at: www.consilium.europa.eu/en/ press/press-releases/2018/05/14/energy-efficient-buildings-council-adopts-reviseddirective
} 
Due to the combustibility of wood and other renewable raw materials, these materials are sometimes treated in order to comply with the strictest safety standards applicable in construction [e.g. NEN $\left.6068^{48}\right]$.

\subsection{Circularity consideration for wooden building materials}

The construction sector uses large volume of raw materials and a large proportion of waste in the Netherlands (approximately 40\%) involves construction and demolition waste. Therefore, it is important to introduce the principles of circularity in this sector. Thereby, construction sector is considered a priority sector according to the European Commission Circular Economy Action Plan ${ }^{2}$ and the Government-wide programme "A Circular Economy in the Netherlands by 2050"1 and the Circular Atlas of the province of Gelderland $d^{4}$. The essence of a circular economy is that products and materials keep circulating while retaining the value of the resources incorporated in it, for as long as possible. And in case new raw materials are necessary this must be supplied by sustainably produced, renewable and widely available raw materials. ${ }^{1}$

Currently, after recycling, the majority of the recycled demolition wasteis used as a foundation material for infrastructure (ground works, road base and hydraulic engineering) and hardly any recycled material is used in construction of new buildings. ${ }^{49}$ To tackle this issue, it is also important to implement sound waste management practices. The change must happen starting from the design stage to consider use of all materials that will be suitable for high-quality reuse. Furthermore cooperation between various stakeholders (architects, contractor, demolition work and waste management) is needed to ensure high grade recycling of materials. The Circular Construction Economy Transition Agenda of the Netherlands describes the strategy for achieving a circular construction economy by $2050 .{ }^{50}$ Furthermore, circular actions were described for different lifecycle phases as depicted in Figure 10.

\footnotetext{
${ }^{48}$ NEN 6068:2020 Determination of the resistance to fire movement between spaces

${ }^{49}$ https://www.eea.europa.eu/themes/waste/waste-management/construction-and-demolition-waste-challenges

${ }^{50}$ https://hollandcircularhotspot.nl/wp-content/uploads/2019/09/Circular-Construction-Economy.pdf
} 


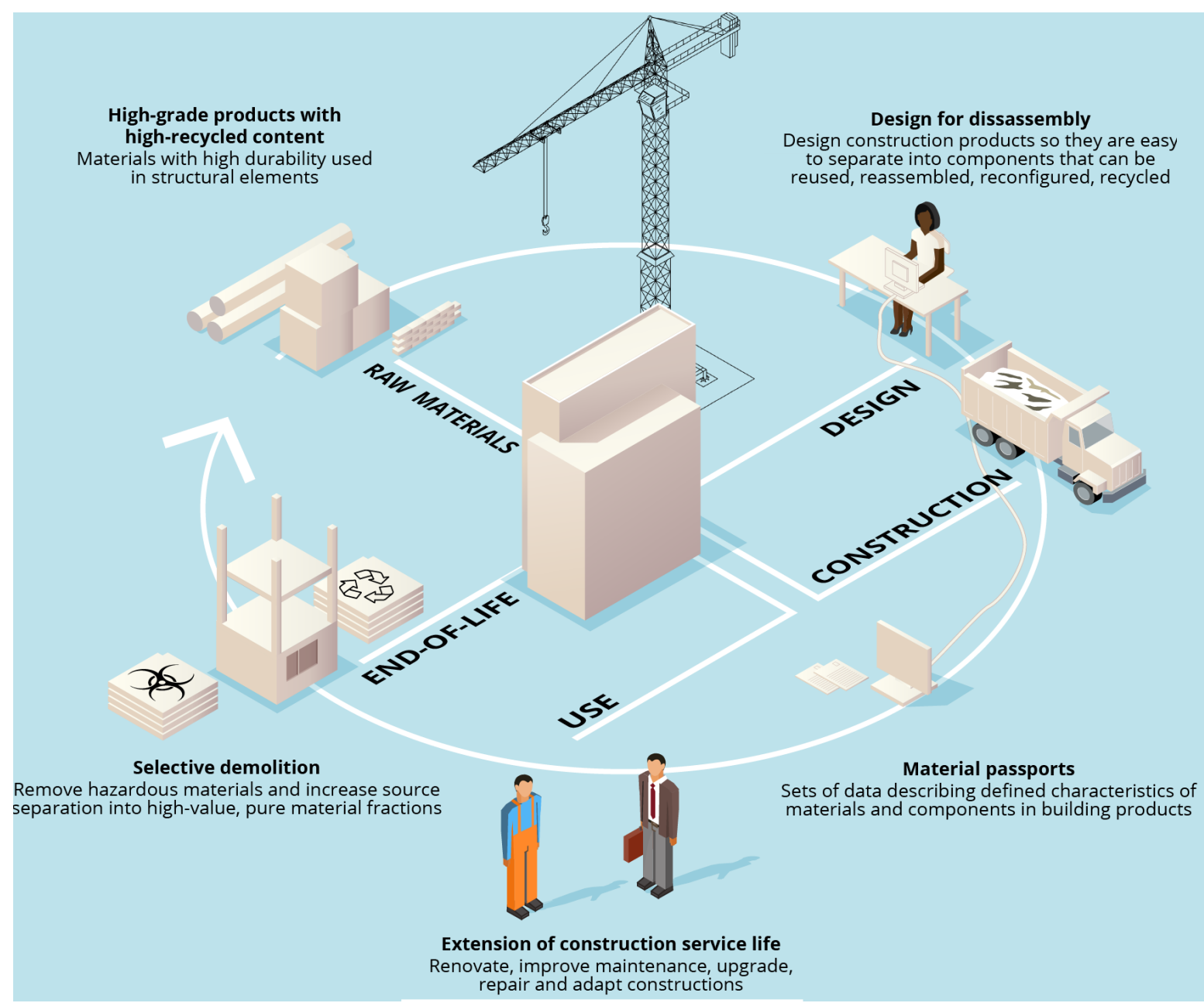

Figure 10 Circular economy action for construction sector over the entire life cycle 51,52

In terms of use of wood and circular economy, the following are important points of consideration:

1. Efficient use of wood

2. Recycling and reuse of wood based building materials, cascading use of wood

3. Replacement of traditional construction materials with wood

4. Extension of lifetime of wooden products

Efficient use of wood

It is important to use wood efficiently. The high-quality wood should be directed for construction and not used for pulp or energy production. The saw logs produced in sawmills are used in buildings and construction. The residues need to be utilized efficiently and not wasted. The bark of the logs and sawdust from processing is used in animal bedding and energy production. The wood chips can be used preferentially for producing paper, otherwise used for energy.

Recycling and reuse of wood based building materials, cascading use of wood Issues:

- Metal screws, nails and bolts are used for fastening wooden parts. In addition, various metal connecting elements can also be used to assemble a wooden construction. Another widely used method includes the application of adhesives to glue wooden surfaces. The use of these materials and also the application of paint however inhibits the high-quality reuse opportunities of wood-based building materials.

- Demolition wood suitable for reuse is not separated and used efficiently. ${ }^{53}$

\footnotetext{
${ }^{51}$ ETC/WMGE, 2020, Construction and Demolition Waste: challenges and opportunities in a circular economy.

52 https://www.eea.europa.eu/highlights/improving-circular-economy-practices-in

${ }^{53}$ Richard Sikkema, Jean Francois Dallemand, Cristina T. Matos, Marijn van der Velde \& Jesus San-Miguel-Ayanz (2017) How can the ambitious goals for the EU's future bioeconomy be supported by sustainable and efficient wood sourcing practices?, Scandinavian Journal of Forest Research, 32:7, 551-558
} 
Options:

- Increasing the separation efficiency of waste collection so that more wood is separated into A, B- and C-wood would make material recycling easier.

- Design for recycling enabling wood to be reused after its functional use, e.g. by avoiding wood and insulation materials to be glued together, or by keeping wooden bars unpainted.

- Cascading use: The reuse or recycling of post-consumer waste fractions, before energy production, after end of life, is called cascading (see Figure 11). Post-consumer lumber waste can be used in production of wood-based panels, such as particleboard, oriented strand board and fiberboard products. This is possible for clean waste wood (A-wood) therefore it is important to apply good waste management to separate this and bring for reuse. Besides improved separation of A-wood, measures need to be taken during design and construction so more of the demolition wood ends up into A-wood, e.g. not applying paint or glue.

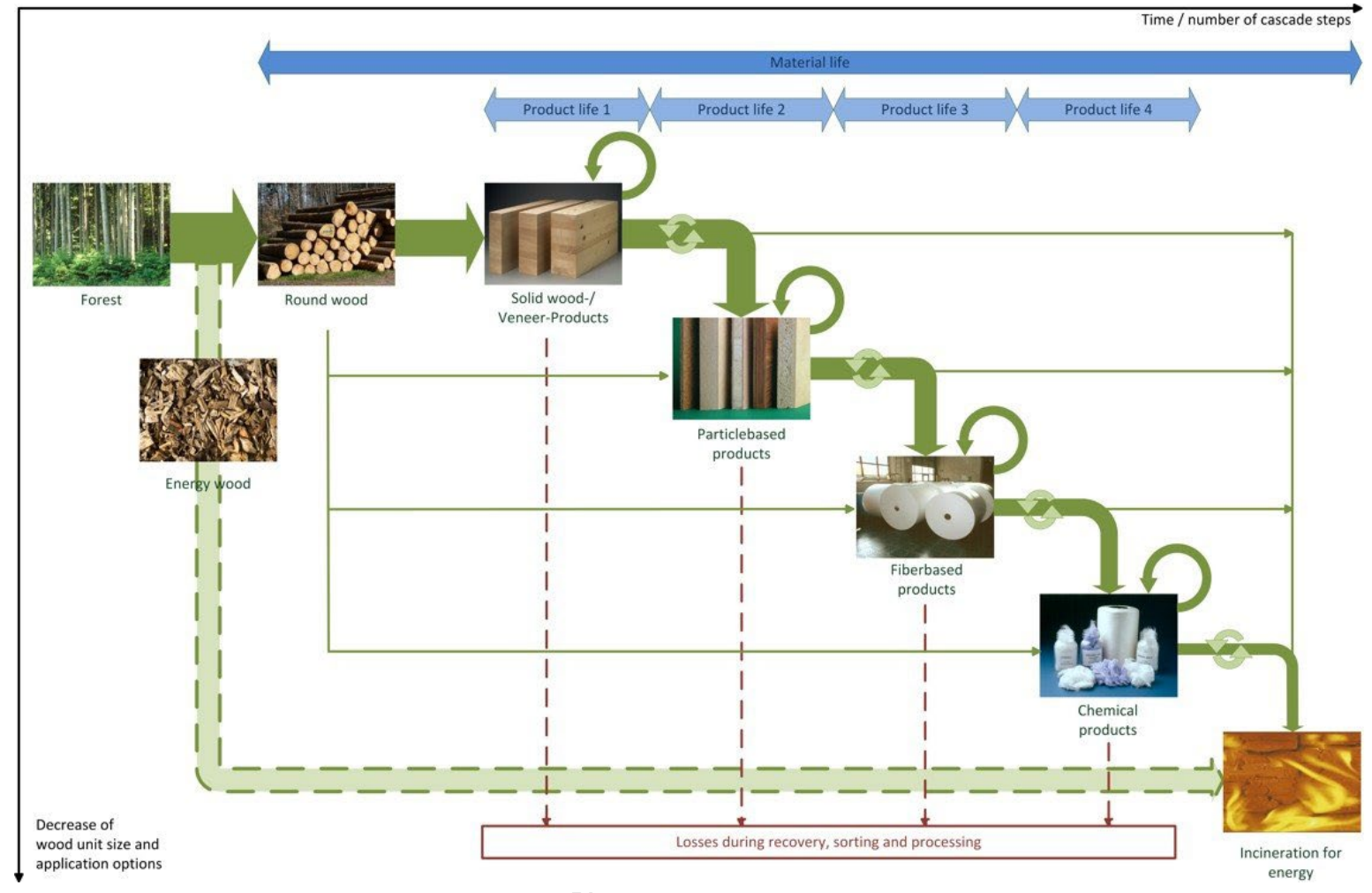

Figure $11 \quad$ Cascading use of wood $^{54}$

Replacement of traditional construction materials with wood

Use of wood in construction gives the possibility to store carbon for a long time during the use phase. They also have good weight to strength ratio meaning less resources are needed for construction as well as for transportation. This could be replacement of concrete structures by timber framed construction, and using window frames of wood instead of synthetic materials. Study by Aalto University shows that a timber framed building is the most material efficient building frame, compared with steel, brick and concrete. ${ }^{55}$

\section{Extension of lifetime of wooden products}

This considers making repairs and the use of wood preservation techniques. This can be through application of preservatives such as borax. Avoid moisture, risk of swelling. Also includes changing the chemical structure of wood to increase the durability, referred to as modified wood. Examples for this include Accoya, Platowood, Nobelwood and Thermowood.

\footnotetext{
${ }^{54}$ https://phys.org/news/2017-12-cascading-wood-sustainability.html

${ }^{55}$ Takano, A., Hughes, M. and Winter, S. (2014). "A multidisciplinary approach to sustainable building material selection: A case study in a Finnish context." Building and Environment 82 (2014): 526-535.
} 


\subsection{Maximum potential availability of wood for use in building industry that can be sustainably harvested in Gelderland/Netherlands}

\subsubsection{Introduction}

During the period 2003-2013, the harvest of wood in the Netherlands as a whole was about $55 \%$ of the total increment in the country. ${ }^{25}$ This is comparable to the situation in Gelderland with a harvest/increment ratio of about 60\% (Chapter 2.4). In theory this would give room for an increase in harvesting without jeopardizing sustainability, which is often interpreted as a non-declining stock. However, in practice there are many barriers to increased mobilization of wood from the forest. Such barriers may be related for example to accessibility, profitability, trade-offs with other functions of the forest, ownership structure and knowledge, and legal aspects. For the Netherlands, Kerr et al. $(2017)^{56}$ identified ownership structure and legal/biodiversity aspects as important barriers. They used a forest simulation model (EFISCEN Space) to identify the wood mobilisation potential for a given region and the main barriers to realise this potential. Here we apply the same approach to the province of Gelderland, with the aim to identify the wood mobilisation potential for Gelderland for different groups of forest owners and to get more insight into the tree species and log sizes that could be mobilised.

\subsubsection{Methods and data}

To determine the maximum amount of wood that can be harvested from the forest with the current management systems, we used the approach as developed by Kerr et al. (2017). ${ }^{56}$ First, the forest is divided into groups that are managed in a similar way. Then, the actual management of each of the identified forest management groups is characterized by the annual probability that a tree is harvested, depending on species and diameter class (Figure 12). These probabilities are derived from the permanent sample plots of the Dutch NFI, for more details on the method see Schelhaas et al. (2018). One of the management groups is selected to represent the "optimal" management with regard to wood production, and the corresponding management is applied to the other management groups to study how much additional wood will be harvested if these forests would be managed according to the "optimal" management.

The management grouping applied here was developed by Arets and Schelhaas (2019). ${ }^{57}$ By comparing actual harvest patterns as deducted from repeated forest inventories and consultations with forest owner and management representatives, they distinguished four types of forest management groups. A first distinction was made between large, often institutionalized owners (organized owners), and non-industrial private (NIPF) owners. Within the group NIPF owners, a further distinction was made between owners having respectively more or less than 5 ha. Within the organized owners, a further distinction was made in forests aimed at multifunctionality and forests aimed at nature conservation, as determined by the actual management subsidy received. The distribution between multifunctional and nature conservation forest differs among the organized owners, but the forests tend to be managed in a similar way, steered by the same market conditions and restrictions by the subsidy schemes. The current subsidy scheme is called Subsidiestelsel Natuur en Landschap (SNL), and has a higher number of subsidy types, more targeted towards specific forest types. ${ }^{58} \mathrm{~N} 16.01$ (Dry forest with production) and N16.02 (Moist forests with production) was classified as forests with a multifunctional management objective and all other types as forests mainly oriented towards nature conservation. Most of the latter types have the restriction that at maximum $20 \%$ of the annual increment may be harvested, on $80 \%$ of the area. On the remaining $20 \%$ more may be harvested, but only if aimed at increasing the nature value.

\footnotetext{
${ }^{56}$ Kerr G, Schelhaas MJ, Nabuurs GJ, 2017 Key determinants and integrated regional solutions of current and potential future mobilisation - Synthesis report. Deliverable 3.3 of the Simwood project

${ }^{57}$ Arets EJMM, Schelhaas MJ. 2019. National Forestry Accounting Plan. Submission of the Forest Reference Level $2021-2025$ for the Netherlands. Ministerie LNV, 2019. 75 p.

${ }^{58}$ https://www.bij12.nl/onderwerpen/natuur-en-landschap/index-natuur-en-landschap/de-index-natuur-enlandschap/natuurtypen/
} 
Thus we distinguish the groups:

organized multifunctional

organized nature-oriented

NIPF large

NIPF small

In this study we used the organized multifunctional forest as the most optimal management regime for producing wood. In addition to the approach by Kerr et al., we applied an even further increased mobilisation scenario by applying the management regime as derived for the forests in NordheinWestfalen (Germany), where the harvest level is higher than in the Netherlands, with a comparable forest situation.

The simulations are done using the EFISCEN Space model, described in more detail in Arets and Schelhaas (2019). ${ }^{57}$ EFISCEN Space models the development of each individual plot from the National Forest Inventory, using a diameter-distribution approach. The starting point for the model are all NFI plots from the NFI- 6 in Gelderland. The increment function was derived specifically for the Netherlands, and management patterns for the different groups were derived based on all plots in the Netherlands, as described in Arets and Schelhaas (2019). ${ }^{57}$ An important issue is that there were hardly any observations in trees of large diameters, so it is uncertain if managers will harvest such trees or not. Arets and Schelhaas assumed a zero harvesting probability in these classes, while we assumed a $1 \%$ probability of harvesting to take place in large diameter trees of coniferous species. ${ }^{57}$ This leads to differences in volumes harvested over the next two decades between the studies, since many trees are expected to grow into these classes given the current diameter distribution (Figure 6).

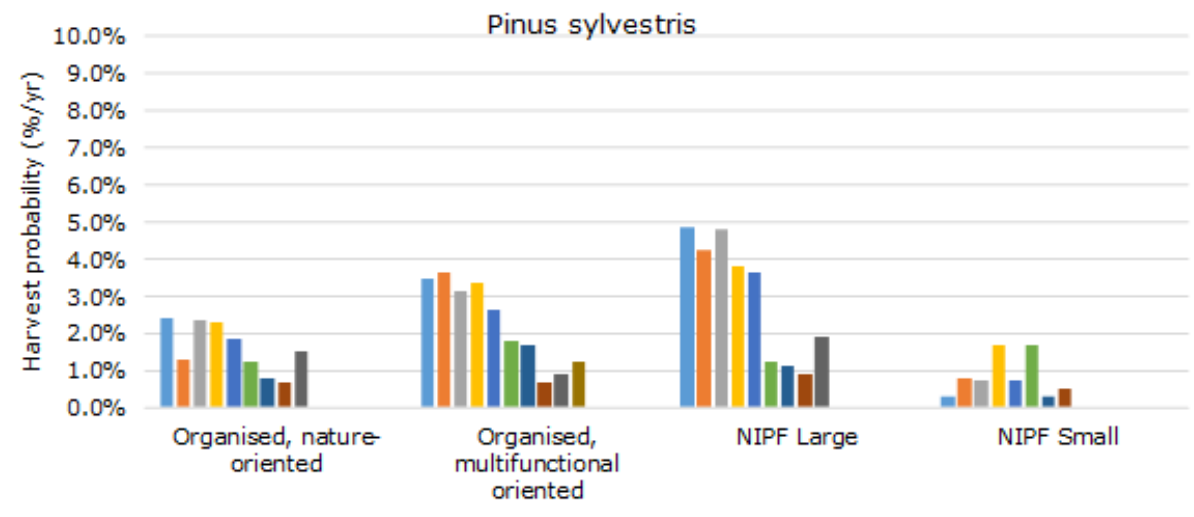

Figure 12 Example of differences in annual harvest probability for Scots pine per management group and per 5-cm diameter class as calculated from the NFI data. The first class (blue bar) is the $5-10 \mathrm{~cm}$ diameter class

\subsubsection{Results}

For Gelderland, 856 NFI plots were available to run the model, representative for an area of 103,400 ha. This is slightly larger than the reported area in Chapter 2.4, due to some uncertainty in the statistical design of the NFI. Overall, in Gelderland 54\% of the forest area is classified as organized multifunctional, $33 \%$ as organized nature-oriented, $11 \%$ as NIPF large and $2 \%$ as NIPF small. Under the baseline scenario, each management group is simulated using its own observed management regime ('business as usual'). Under the medium mobilization scenario, all management groups are simulated using 'organized multifunctional management'. Under the high mobilization scenario, all management groups are simulated using the State Forest Service management from NordrheinWestfalen.

Under the baseline scenario, the harvest declined slightly from the current $457,000 \mathrm{~m}^{3}$ per year to $358,000 \mathrm{~m}^{3}$ per year around 2040 (Figure 13). The average growing stock (i.e. the amount of $\mathrm{m} 3$ of wood in the forest of all live trees together) increased from $236 \mathrm{~m}^{3} / \mathrm{ha}$ in 2013 to $270 \mathrm{~m}^{3} / \mathrm{ha}$ in 2040 (Figure 14), with a substantial increase of volume in the diameter classes $>50 \mathrm{~cm}$ (Figure 15). The medium mobilisation scenario started with a harvest level of $522,000 \mathrm{~m}^{3}$ per year, declining to $400,000 \mathrm{~m}^{3}$ per year in 2040. 
On average, this scenario mobilised $51,000 \mathrm{~m}^{3}$ per year extra as compared to the baseline (Figure 13; Table 4). As a consequence, the build-up of growing stock was slower, reaching $256 \mathrm{~m}^{3} / \mathrm{ha}$ in 2040 . The high mobilisation scenario started with a harvest level of 701,000 million $\mathrm{m}^{3}$ per year, but also declined to $400,000 \mathrm{~m}^{3}$ per year in 2040 . On average, the high mobilisation scenario mobilised $129,000 \mathrm{~m}^{3}$ per year extra as compared to the baseline (Table 4). In this scenario, the growing stock decreased to $227 \mathrm{~m}^{3} /$ ha in 2040, indicating a harvest level that exceeds the annual increment, which is generally seen as being an unsustainable practice.

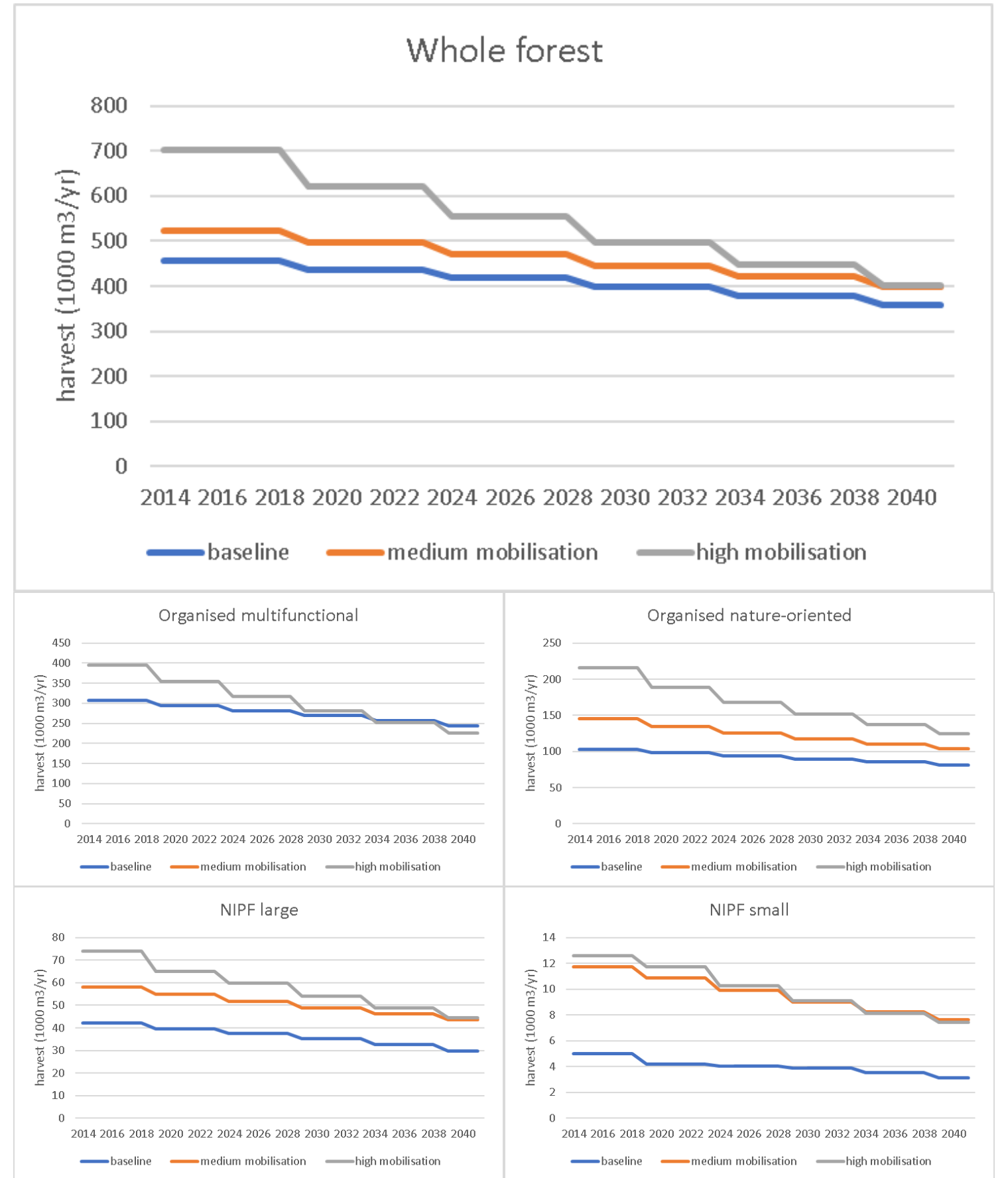

Figure 13 Projected harvest amount for the forest as a whole and per management group 


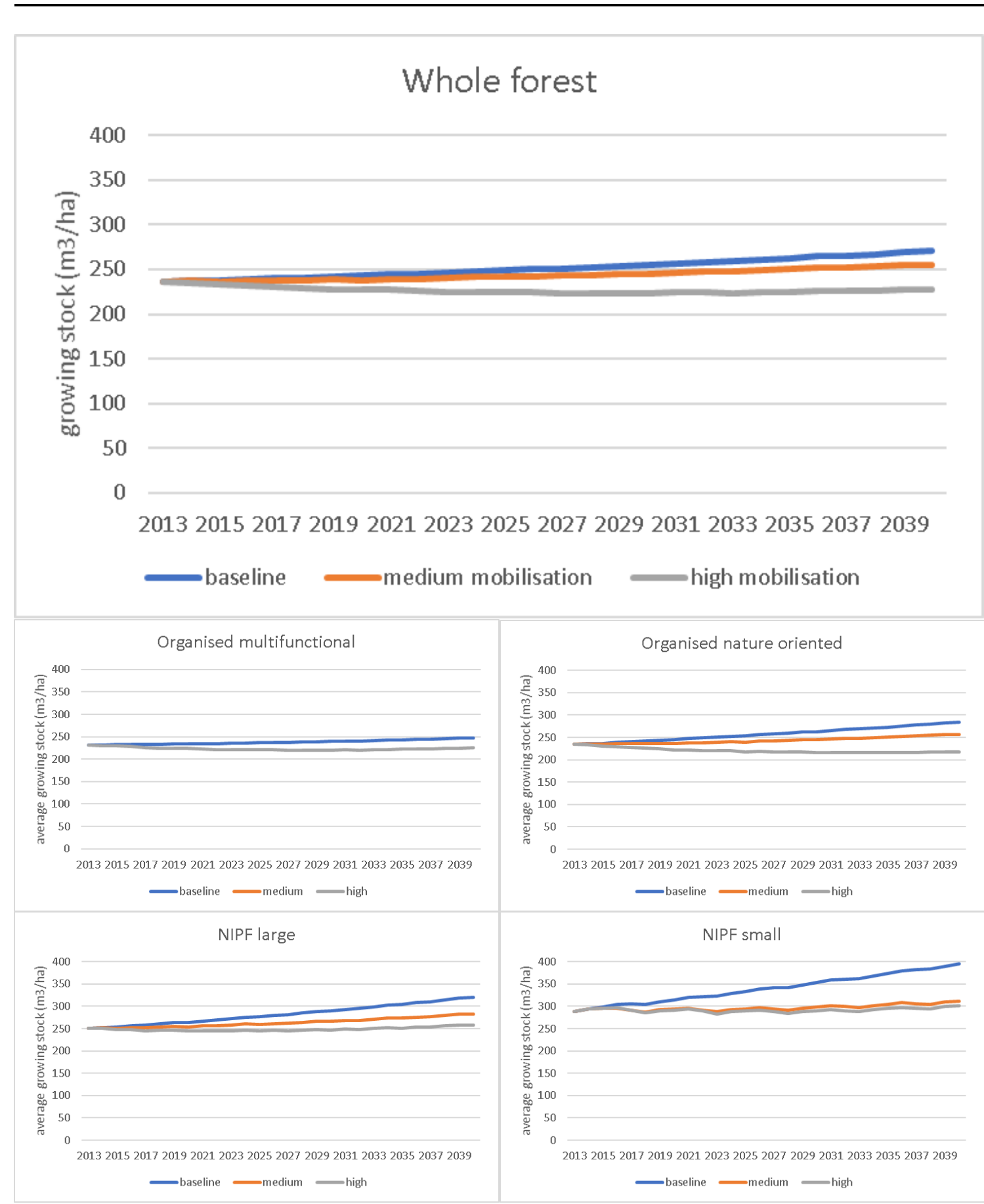

Figure $14 \quad$ Projected growing stock for the forest as a whole and per management group 


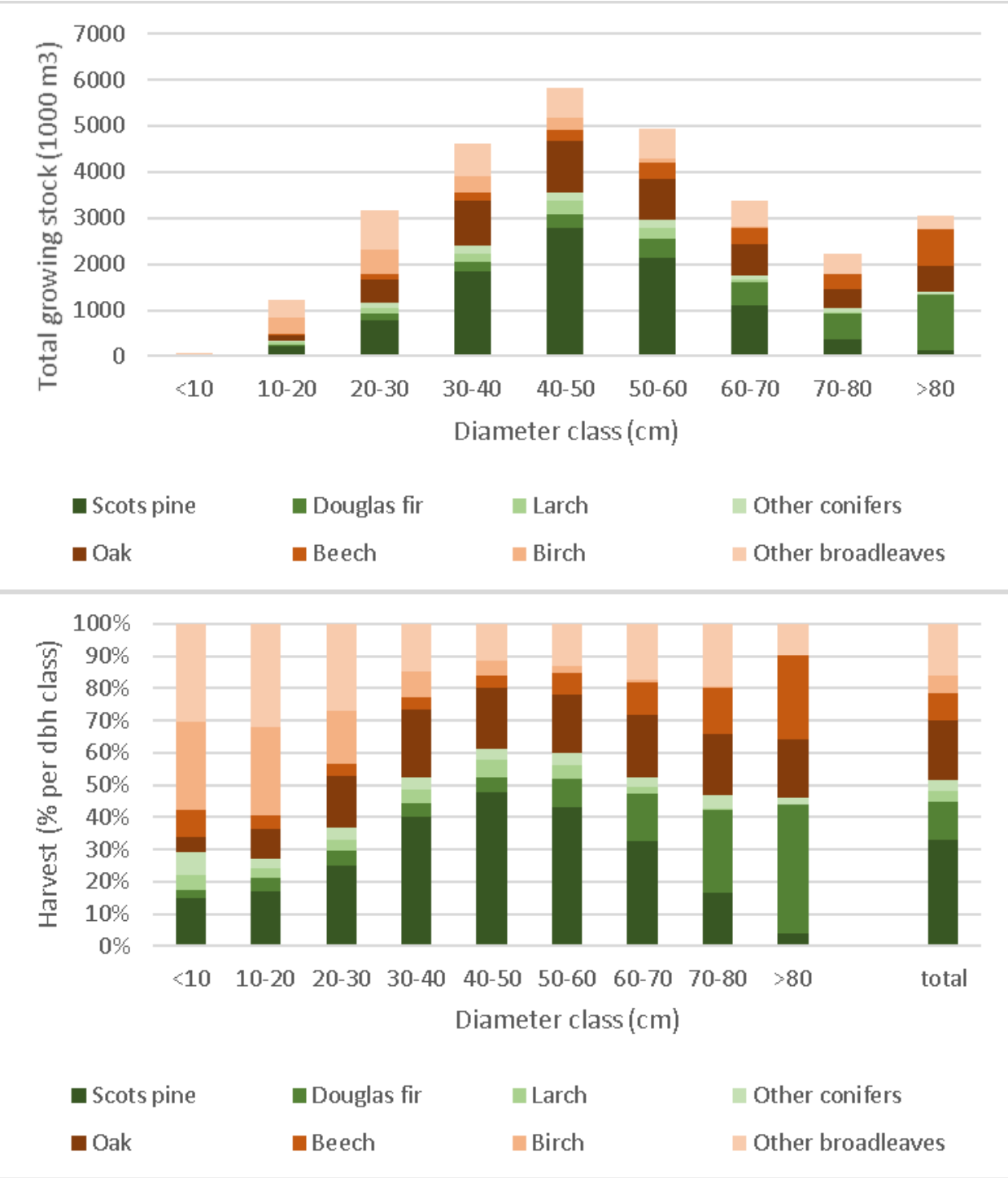

Figure 15 Simulated species and diameter distribution of the growing stock in 2040 under the baseline scenario, in $1000 \mathrm{m3}$ (top) and relative (bottom)

Table 4

Area and average harvest, averaged over the whole simulation period (2013 - 2040), per management group.

\begin{tabular}{lllll}
\hline & area & baseline & $\begin{array}{l}\text { medium } \\
\text { mobilisation }\end{array}$ & $\begin{array}{l}\text { high } \\
\text { mobilisation }\end{array}$ \\
\hline & ha & $1000 \mathrm{~m}^{3} / \mathrm{yr}$ & $1000 \mathrm{~m}^{3} / \mathrm{yr}$ & $1000 \mathrm{~m}^{3} / \mathrm{yr}$ \\
Multifunctional organised & 56,000 & 275 & 275 & 304 \\
Nature-oriented organised & 34,300 & 92 & 123 & 164 \\
NIPF large & 11,200 & 36 & 51 & 58 \\
NIPF small & 1,900 & 4 & 10 & 10 \\
total & 103,400 & 407 & 458 & 536 \\
\hline
\end{tabular}

\section{Organised multifunctional}

The growing stock of the forests managed as multifunctional organised increased slightly in the baseline scenario, from $231 \mathrm{~m}^{3} / \mathrm{ha}$ in 2013 to $248 \mathrm{~m}^{3} / \mathrm{ha}$ in 2040 . Under the high mobilisation scenario, it decreased to $225 \mathrm{~m}^{3} / \mathrm{ha}$ in 2040 , indicating that the harvest is exceeding the increment. For the high mobilisation scenario we applied the management pattern as observed in NordrheinWestfalen. Overall this yields a harvest that is $29,000 \mathrm{~m}^{3} /$ year higher, but for some species the harvest is actually lower, notably for larch $\left(-5,000 \mathrm{~m}^{3} /\right.$ year) and other broadleaves $\left(-13,000 \mathrm{~m}^{3} /\right.$ year $)$. Scots pine showed the highest increase with $28,000 \mathrm{~m}^{3} /$ year extra, located in the diameter classes 20 $50 \mathrm{~cm}$, with the largest increase in $40-50 \mathrm{~cm}$ (Figure 16; Figure 17). 
Douglas fir had an overall increase in harvest of $4,000 \mathrm{~m}^{3} /$ year. This was mostly realised in the class $50-60 \mathrm{~cm}\left(+17,000 \mathrm{~m}^{3} /\right.$ year $)$ and to a smaller extent in the classes $10-50 \mathrm{~cm}\left(+6,000 \mathrm{~m}^{3} /\right.$ year $)$, but with a trade-off of lower harvests in classes above $60 \mathrm{~cm}\left(-19,000 \mathrm{~m}^{3} /\right.$ year $)$. The latter is caused by two factors. Firstly, harvest in the lower classes is more intensive, so less trees grow to higher diameters. Secondly, the harvest probability in higher diameter classes in Nordrhein-Westfalen was zero, either because of lack of observations, or because trees of these dimensions are simply not harvested. The harvest level in beech was 9,000 $\mathrm{m}^{3} /$ year higher than in the baseline, entirely realised in trees larger than $70 \mathrm{~cm}$. Birch had increased harvest levels in all diameter classes, in total 6,000 $\mathrm{m}^{3} /$ year extra.

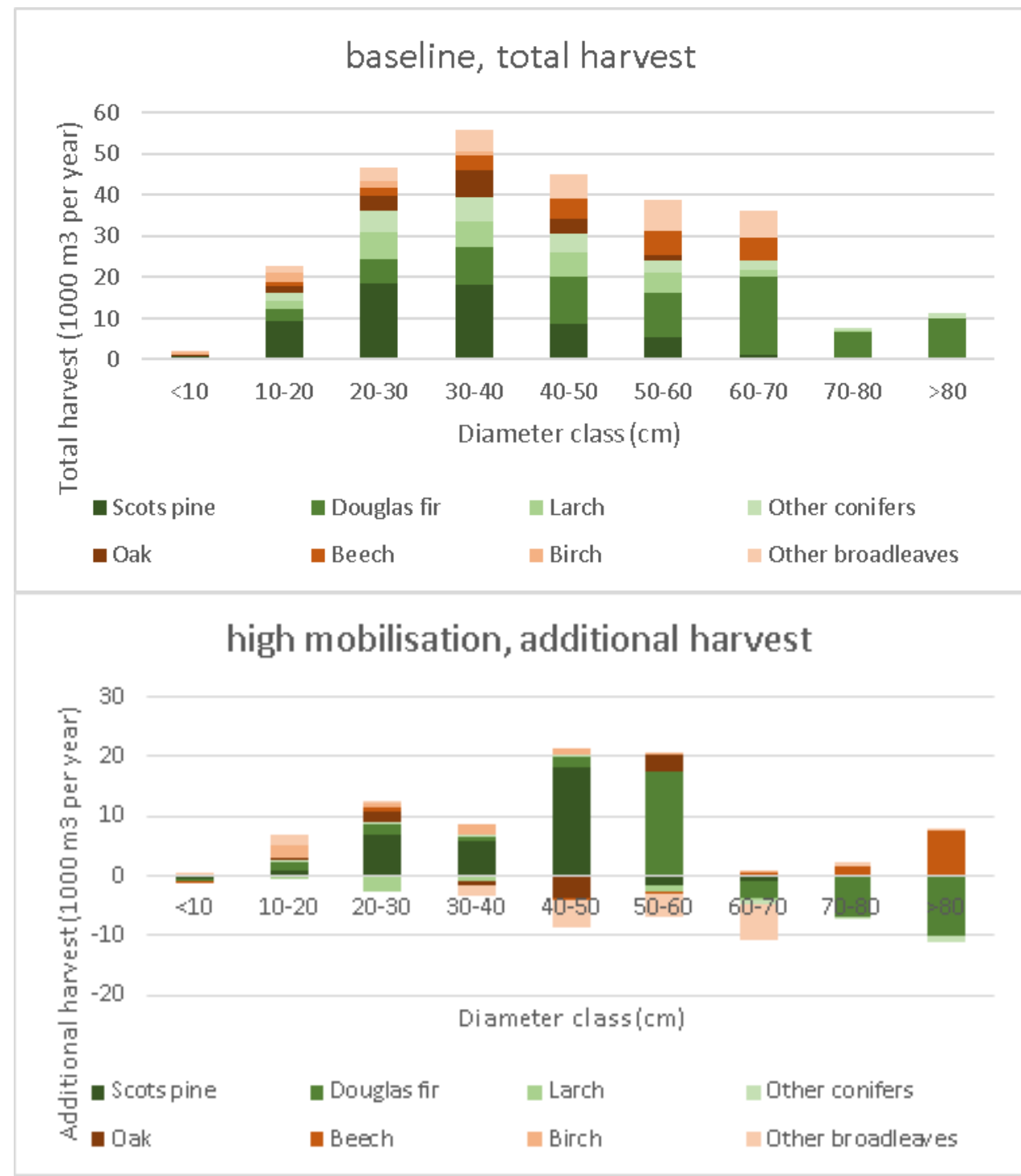

Figure 16 Harvest by species and diameter class for organised multifunctional management, for the baseline (top) and additional compared to baseline for the high mobilisation scenario (bottom) 


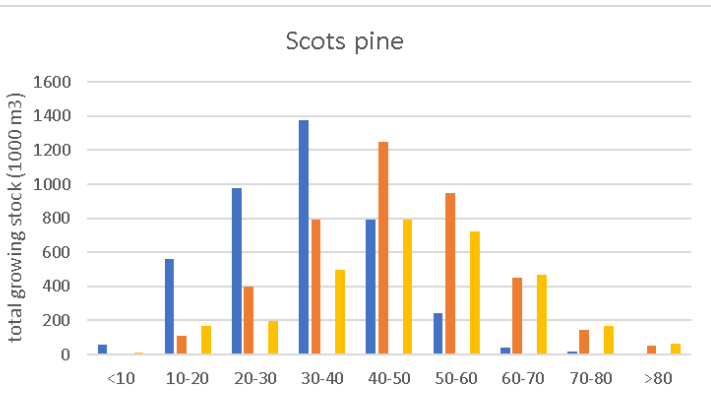

abaseline 2010 m baseline $2040 \backsim$ medium mobilisation $2040 \backsim$ high mobilisation 2040

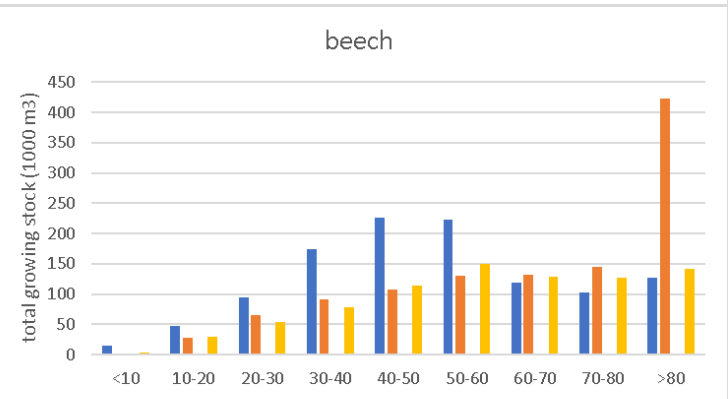

- baseline 2010 m baseline 2040 medium mobilisation $2040 \backsim$ high mobilisation 2040

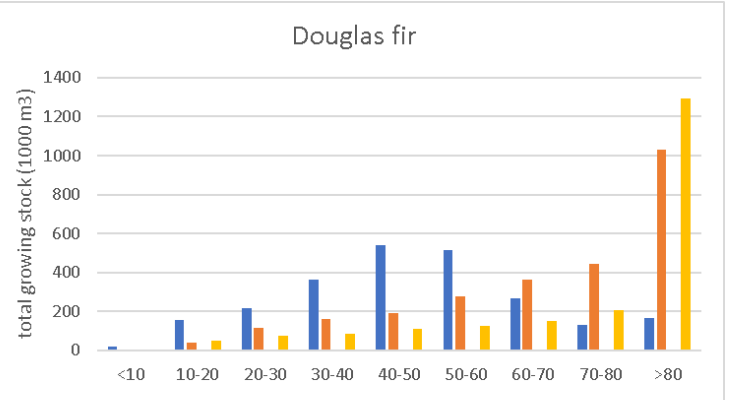

mbaseline 2010 m baseline 2040 medium mobilisation $2040 \backsim$ high mobilisation 2040

birch

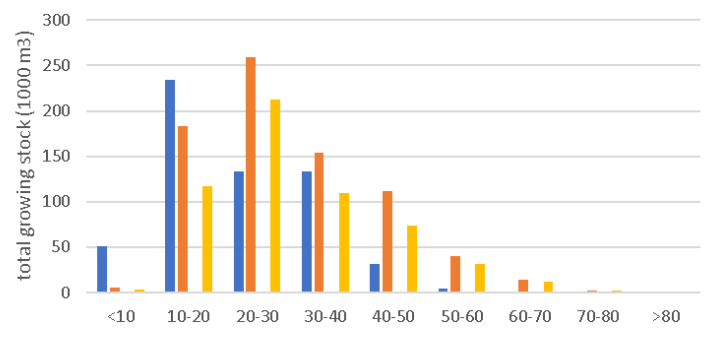

- baseline 2010 m baseline 2040 medium mobilisation $2040 \cong$ high mobilisation 2040

Figure 17 Growing stock per diameter class for selected species under multifunctional organised management, in 2010 and as projected for 2040 under the different scenarios

\section{Organised nature-oriented}

The largest additional mobilisation potential was located in forests with a nature conservation objective. The mobilisation scenarios (Table 4) indicated a potential increase in annual harvest level of $31,000-72,000 \mathrm{~m}^{3}$, but the latter harvest level would be unsustainable, causing a decrease in the average growing stock over time. Scots pine had the highest potential for increased harvest, ranging from 14,000 to $41,000 \mathrm{~m}^{3}$ (Figure 18 ). Douglas fir had only a small potential of $1,500-3,000 \mathrm{~m}^{3}$ (Figure 19). Oak had a potential of $5,000 \mathrm{~m}^{3} /$ year extra, in diameter classes up to $60 \mathrm{~cm}$. However, larger diameter classes also showed a substantial increase in volume, but no additional harvest. Beech had a potential of 5,000-13,000 $\mathrm{m}^{3} /$ year extra, mostly in the range $50-70 \mathrm{~cm}$ and $>80 \mathrm{~cm}$. Birch had a potential of $0-4,000 \mathrm{~m}^{3} /$ year and other broadleaves about 3,500 $\mathrm{m}^{3} /$ year, both in diameter classes up to $40 \mathrm{~cm}$. 


\section{baseline, total harvest}
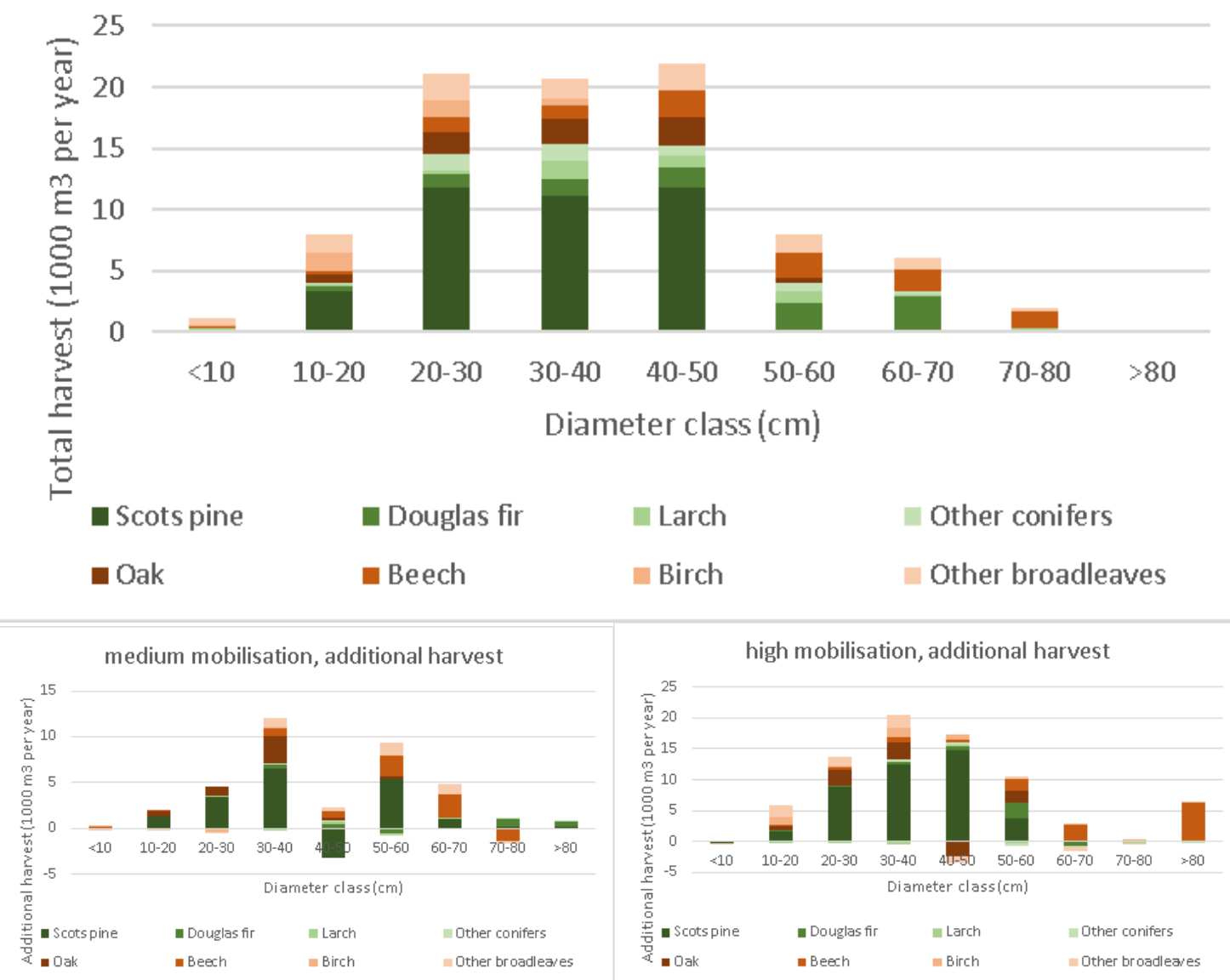

Figure 18 Harvest by species and diameter class for organised nature-oriented management, for the baseline (top) and additional compared to baseline for the medium and high mobilisation scenario (bottom)

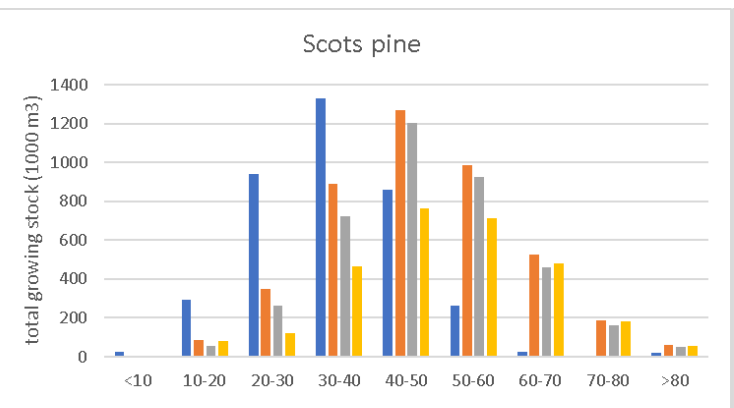

- baseline 2010 maseline 2040 medium mobilisation 2040 high mobilisation 2040

oak

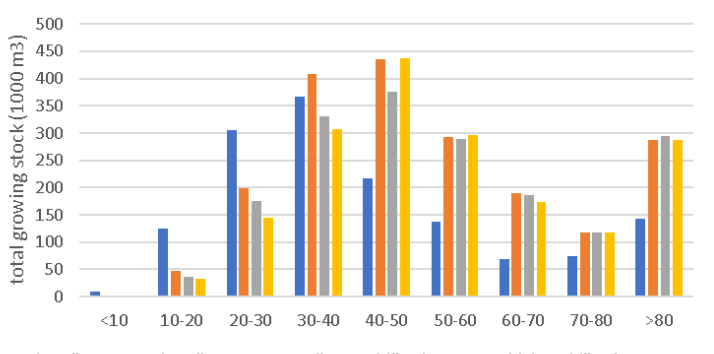

—baseline 2010 — baseline 2040 - medium mobilisation 2040 - high mobilisation 2040

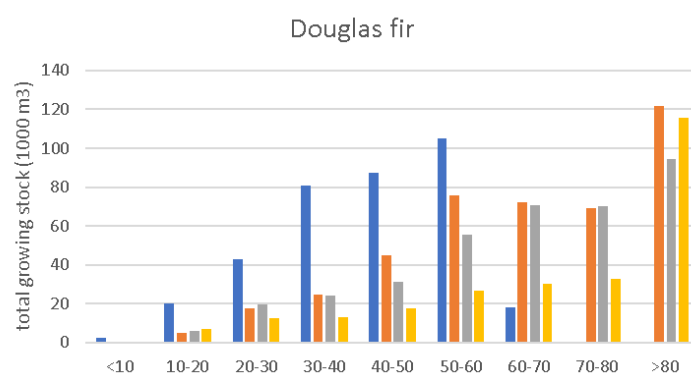

maseline 2010 baseline 2040 medium mobilisation 2040 high mobilisation 2040

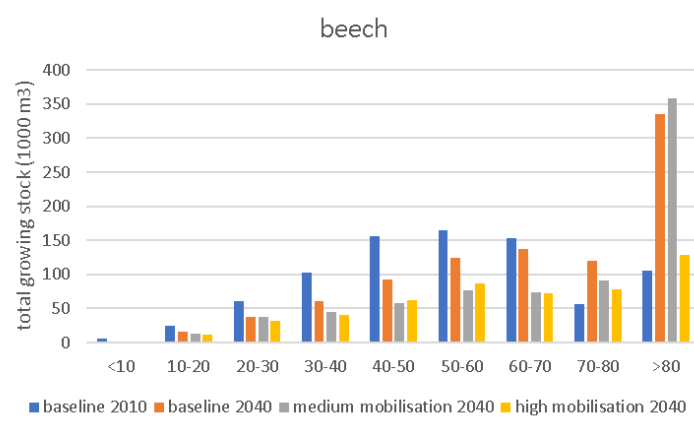

Figure 19 Growing stock per diameter class for selected species for organised natureoriented management, in 2010 and as projected for 2040 under the different scenarios 


\section{NIPF large}

The mobilisation potential in the NIPF large group ranges from $14,000 \mathrm{~m}^{3}$ per year in the medium mobilisation scenario to $22,000 \mathrm{~m}^{3}$ per year in the high mobilisation scenario (Table 4 ). Both mobilisation scenarios can be sustained over the simulated period of 30 years, without decreasing the growing stock (Figure 14). The species group 'other broadleaves' had a potential of 10,600 $\mathrm{m}^{3}$ per year in the medium mobilisation scenario. The potential of 'other broadleaves' in the high mobilisation scenario was $5,000 \mathrm{~m}^{3}$ per year. Pine had a potential of 4,800 $\mathrm{m}^{3}$ per year in the high mobilisation scenario. For oak, there was zero additional harvest in the diameter classes in both mobilisation scenarios (Figure 20), causing a substantial accumulation of volume in the higher diameter classes (Figure 21). This was due to zero harvest probability for higher diameter classes of oak in the applied management regimes in both mobilisation scenarios. The zero harvest probability is caused by lack of observations, or because trees of these dimensions are simply not harvested. The harvest of Douglas fir was actually lower in the medium mobilisation scenario $\left(-1,000 \mathrm{~m}^{3}\right)$, most notably in the $50-60 \mathrm{~cm}$ diameter class $\left(-3,000 \mathrm{~m}^{3}\right)$.

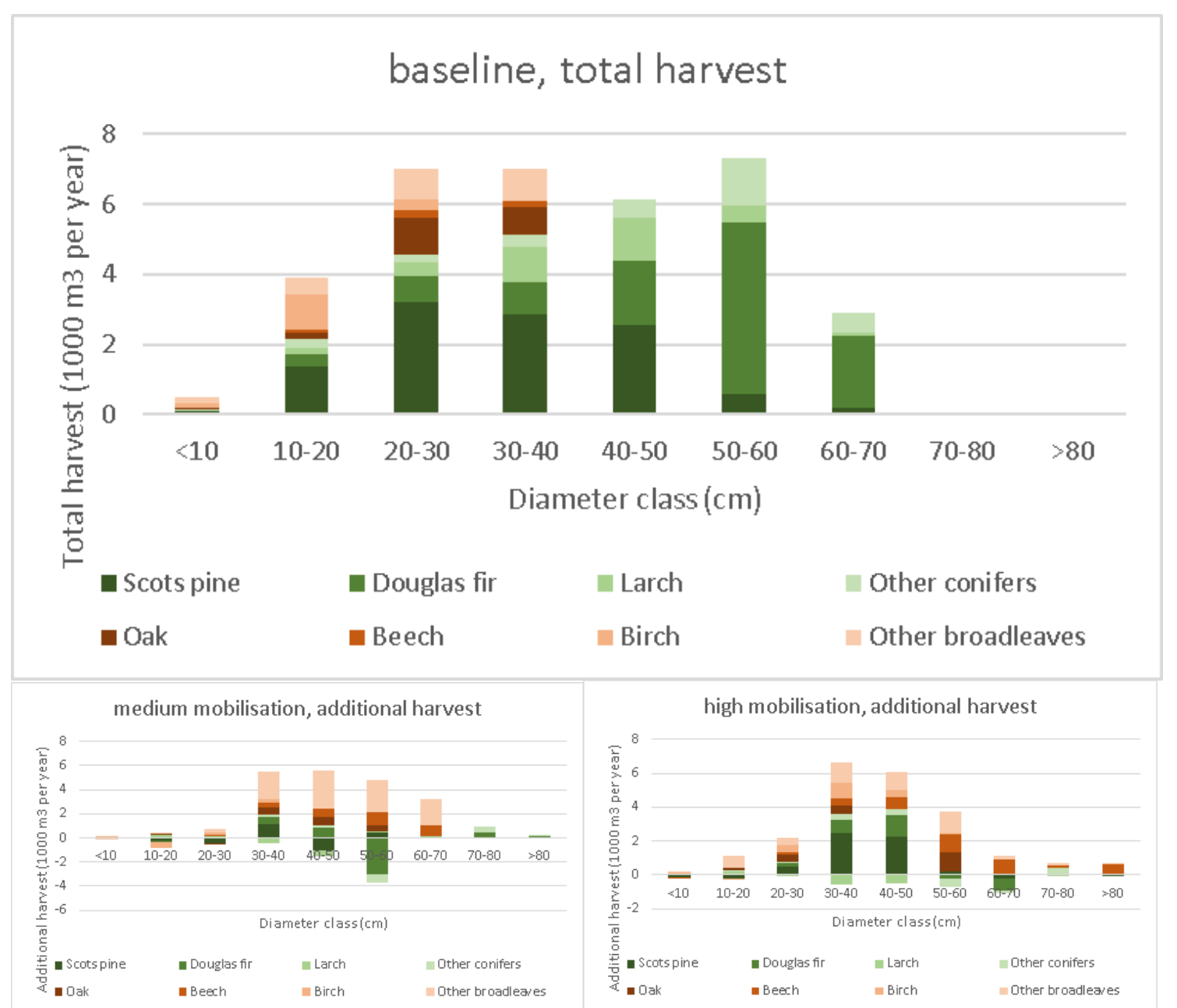

Figure 20 Harvest by species and diameter class for NIPF large management, for the baseline (top) and additional compared to baseline for the medium and high mobilisation scenario (bottom) 

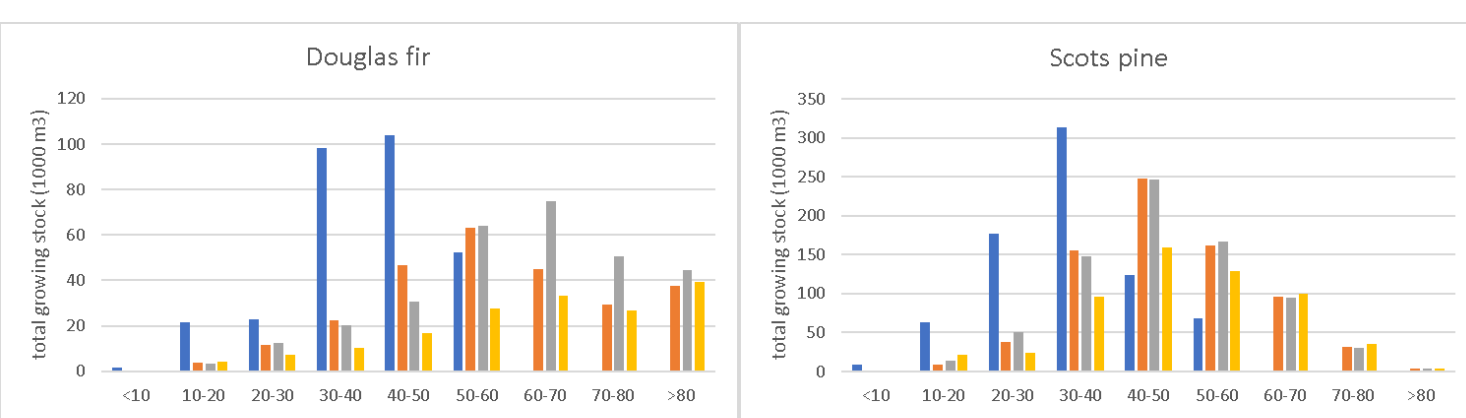

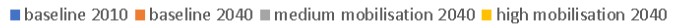

चbaseline 2010 = baseline 2040 m medium mobilisation 2040 = high mobilisation 2040

beech

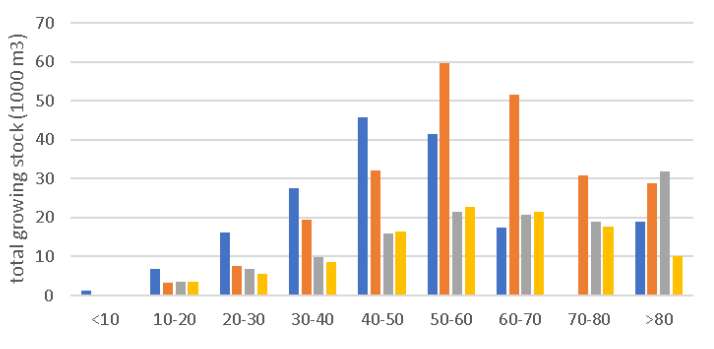

oak

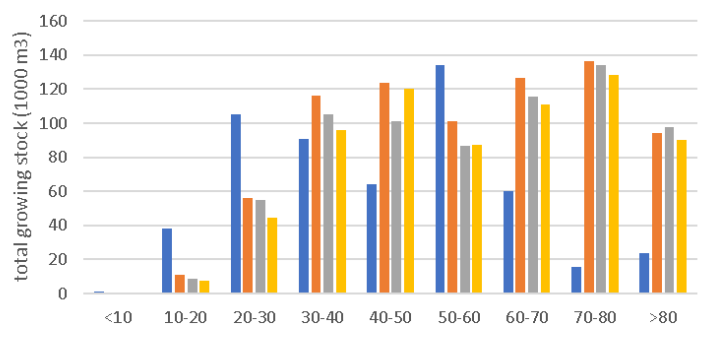

mbaseline 2010 maseline $2040 \cong$ medium mobilisation $2040 \backsim$ high mobilisation 2040

Figure $21 \quad$ Growing stock per diameter class for selected species for NIPF large management, in 2010 and as projected for 2040 under the different scenarios

\section{NIPF small}

The group NIPF small showed a mobilisation potential of 5,400-5,700 $\mathrm{m}^{3}$ annually (Table 4). The potential is divided over the different species groups, without striking differences (Figure 22). All scenarios show an accumulation of wood in the large diameter classes (Figure 23). 


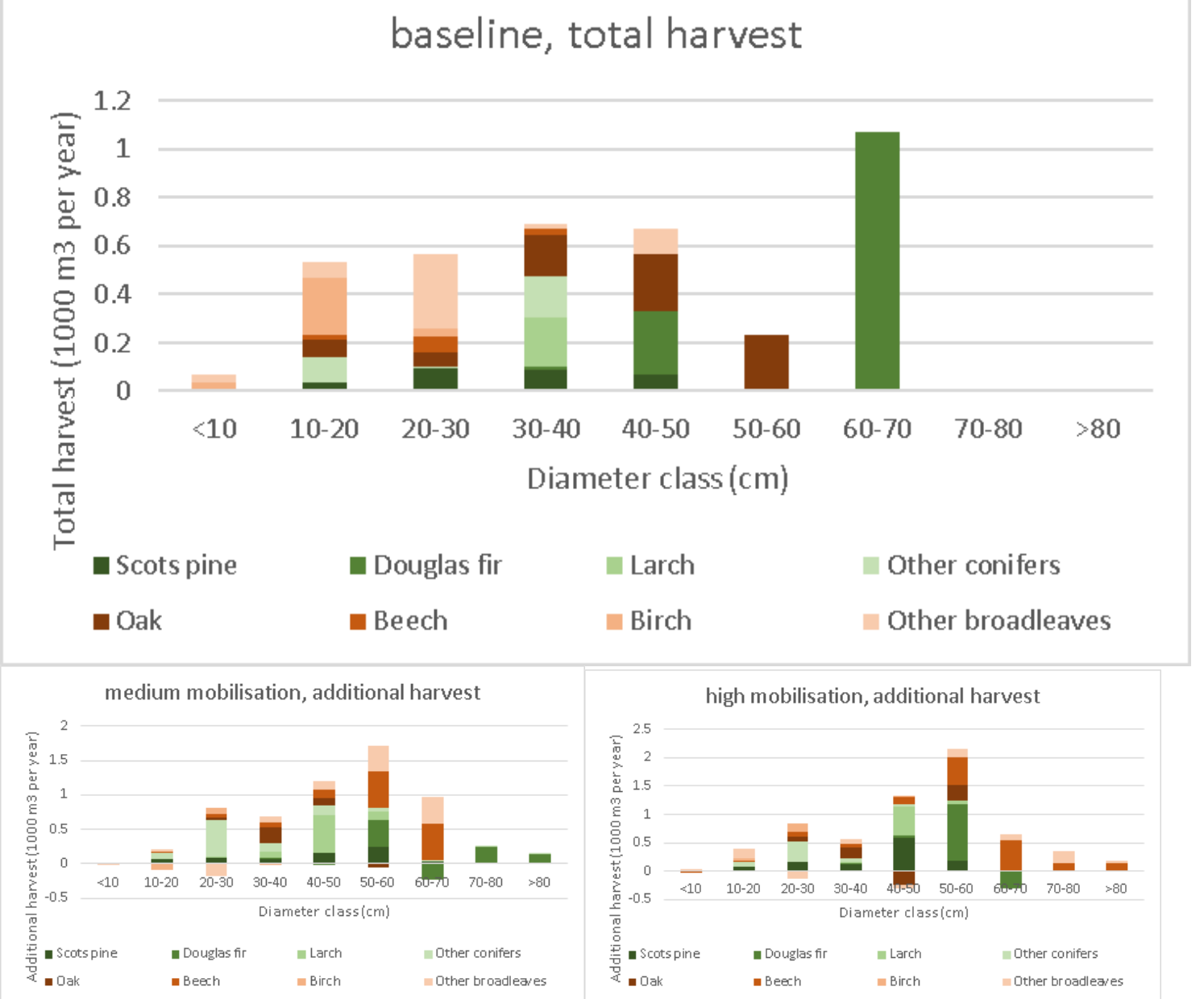

Figure 22 Harvest by species and diameter class for NIPF small management, for the baseline (top) and additional compared to baseline for the medium and high mobilisation scenario (bottom)

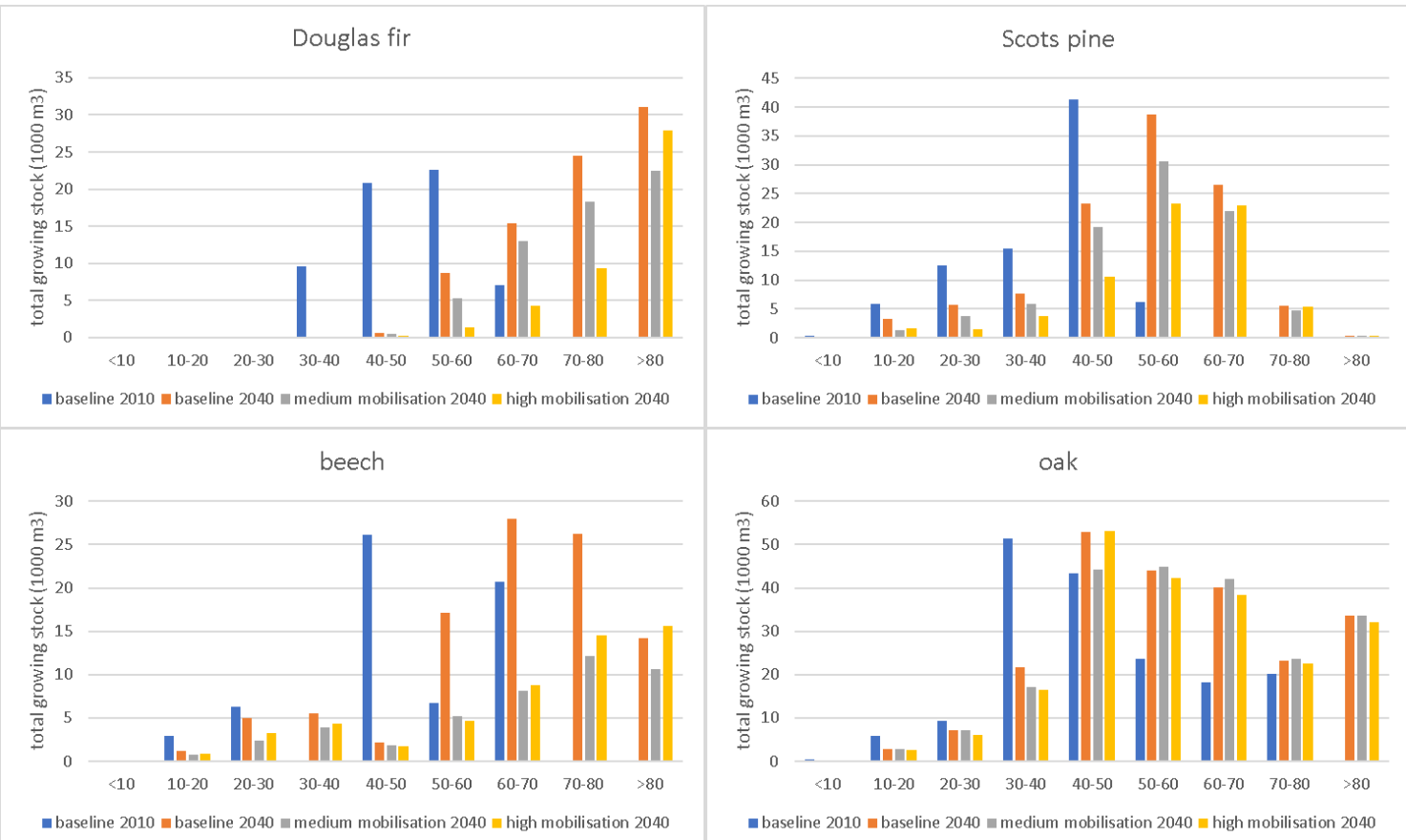

Figure 23 Growing stock per diameter class for selected species for NIPF small management, in 2010 and as projected for 2040 under the different scenarios 


\subsubsection{Discussion}

Currently most wood volume is found in diameter class $30-40 \mathrm{~cm}$, with hardly any volume in classes over $60 \mathrm{~cm}$. In the baseline scenario for 2040 the peak shifted to $40-50 \mathrm{~cm}$, with a large increase in the diameter classes larger than $50 \mathrm{~cm}$. This pattern was visible in all species except birch, which became more dominant in the smaller diameter classes, as it has been an abundant species in the regeneration during the past decades. Also the group other broadleaves increased its share substantially in the classes up to $30 \mathrm{~cm}$. These are mostly shrub-forming species like hazelnut, Sorbus aucuparia and Prunus species. The share of broadleaves in these classes increased to $70 \%$. However, these results are subject to considerable uncertainty since there is no regeneration module in the current version of EFISCEN Space, so we cannot simulate the exact species distribution in the small diameter classes. The accumulation of volume in the higher diameter classes indicates a potential for increased harvest in the near future. The mobilisation scenarios generally tap into this by harvesting more trees from these diameter classes, with some differences in species and diameters depending on the scenario and the management group. Oak and the group "other broadleaves" also show an accumulation in large diameter classes but are not harvested in any of the mobilisation scenarios.

Increased harvests in high diameter classes in a certain species could lead to a decrease in overall volume for that species, as there is a general lack of trees in the smaller diameter classes. If the potential in all these species would be utilised at the same time, harvest would exceed increment and the growing stock would decrease, as happened in some scenarios for some management groups. This does not per se imply that the forest management is unsustainable, as forest managers might have their reasons to decrease the growing stock. A decrease in growing stock would for example be desirable to decrease the risk of losses due to natural disturbances, but also if the aim is to get a more balanced distribution over age or diameter classes. In the latter case it should be accompanied by efforts to increase the number of trees in the lower diameter classes, for example by planting and/or protection against damage by game (deer). However, this should be carried out and communicated very carefully as recent efforts by the State Forest Service in this direction were heavily criticized by the general public and in the press. Therefore, not all this potential can be realised in the short term, and choices have to be made on what species and how much is feasible and desirable.

Forests managed as 'organised multifunctional' showed a potential of ca. 29,000 $\mathrm{m}^{3}$ per year, but at the cost of a slight decrease in growing stock. This indicates that the current harvest levels in the organised multifunctional group cannot be raised much without discussion on its sustainability, but at the same time this group shows an aging effect, with an increase of large trees and a lack of regeneration. The potential for wood mobilisation in forests with a nature conservation objective was $31,000-72,000 \mathrm{~m}^{3}$ per year. This is larger than in the organised multifunctional forests because the harvest level is much lower in the forest with a nature conservation objective. However, increased harvesting in forests with a nature conservation objective would require a change in the conditions of the current subsidy scheme, a change in the attitude and management goals of the owners, and will probably evoke heated discussions by the public and NGOs about the conflict between nature conservation and wood production. Therefore, it is very unlikely that this potential can be realised. The potential for wood mobilisation in forests managed by the 'NIPF large owner' group was 14,000$22,000 \mathrm{~m}^{3}$ per year. However, the NIPF large group is very heterogenous, with many owners valuing nature and landscape amenity as high or even higher than wood production, and it might be difficult to convince them to harvest more.

The potential for wood mobilisation in forests managed by the NIPF small owner group was 5,400$5,700 \mathrm{~m}^{3}$ per year. The 'NIPF small' group owns about 1,900 ha. Given the size of their property $(<5$ ha), this would amount to approximately a thousand forest owners. Practice shows that these owners are hard to reach (Clerkx et al. 2016), and the effort to mobilise this potential clearly outweighs the revenue. In summary, the potential in the groups organised nature oriented and NIPF small are very unlikely to be realised. At least part of the potential in organised multifunctional and NIPF large should be feasible to mobilise with reasonable effort, as these groups generally have larger properties with professional managers and are already harvesting for production purposes. Thus, the harvest could realistically be increased at maximum by about $40-50,000 \mathrm{~m}^{3}$ annually $(10 \%$ compared to the current harvest), mainly consisting of trees in the high diameter classes, with some choice in what species to harvest. 
The simulated harvests for the baseline and mobilisation scenarios have uncertainty in the high diameter classes. Because these trees are currently very rare, they are hardly covered in the inventory, and the number of observations is too low for a correct estimation of harvesting probabilities. If the current harvest probabilities in these classes would be underestimated for the baseline scenario, the simulated potentials in the mobilisation scenarios would be lower than presented here, but the baseline harvest would probably be more stable than currently projected. Furthermore, the National Forest Inventory (the data source for this study) was designed to give an adequate picture of the situation at national level with 1 plot per ca. 120 ha of forest. Results for groups or areas with a low number of sample plots in the inventory have higher associated uncertainties, which would at least be the case for the NIPF small group in this study. Many of the large owners have their own inventory systems, with a sampling density of 1 plot per 1-10 ha. These data could be used to refine the picture as sketched here and should be used to make decisions at the property level.

The drought of the years 2018, 2019 and 2020 caused dieback in spruce and larch in Gelderland and to lesser extent in Douglas fir, but so far quantitative data are lacking. This may lead to short-term increased harvesting (salvaging) of these species, and deviations as compared to the simulations presented here. Part of the dead trees may remain in the forest and will be unavailable for the market.

\subsection{Matching wood types with applications}

\subsubsection{Matrix wood for construction materials}

For the assessment of suitability of domestically grown wood for building and construction applications, the current quality demands on commercial timber and engineered wood products have to be considered. Table 1 gives an overview of the temperate species that are allowed to be used as structural timber, as well as their durability and suitability for use outdoors. The workability aspects are important for the selection of the species and are strongly dependent on the density, but also on the homogeneity of the wood, the ease of planning and the mechanical properties (flexibility, dimension stability, etc.). Construction wood in the Netherlands is most commonly derived from softwood species, such as Norway spruce, pine and Douglas fir. Common hardwood species such as oak and beech are more expensive and more difficult to process. For outdoor uses, such as cladding and window frames, the softwood species are considered less suitable as additional protection coatings are essential.

\subsubsection{Timber}

Important aspects for commercial use of wood and engineered wood products are their standard sizes for use in building materials. Lumber sizes are usually given in nominal measurements in inches. The actual measurements are the final size after it has been planed smooth on all 4 sides. For example the nominal size $1 \times 2$ inch, corresponds to actual size of $3 / 4 \times 1 \frac{112}{2}$ inch or $19 \times 38 \mathrm{~mm}$. Sawn wood can be made from many sources and can have range of commercial dimensions and uses (see Table 5). 


\begin{tabular}{|c|c|c|c|c|}
\hline Wood source & Product & $\begin{array}{l}\text { Dutch } \\
\text { name }\end{array}$ & $\begin{array}{l}\text { Commercial dimensions } \\
\text { mm (nominal) }\end{array}$ & Use \\
\hline \multicolumn{5}{|l|}{ Softwood: } \\
\hline \multirow[t]{3}{*}{ Pine, spruce, larch } & Beams & Balken & $\begin{array}{l}50 \times 50 / 75 / 100 / 150 \\
63 \times 160 / 175 \\
75 \times 175 / 200\end{array}$ & $\begin{array}{l}\text { Construction wood, } \\
\text { purlin }\end{array}$ \\
\hline & Battens & Latten /rachel & $22 \times 50 / 63 / 75$ & Trussing and battening \\
\hline & Planks & Planken & $\begin{array}{l}22 \times 100 / 125 / 150 \\
32 \times 100 / 125 / 150 / 200\end{array}$ & Planks, plinth, batten \\
\hline \multirow[t]{2}{*}{ Larch, Douglas } & $\begin{array}{l}\text { Live edge } \\
\text { wood }\end{array}$ & Schaaldelen & $20 \times 150 \times 3000$ & \\
\hline & & & $20 \times 400 \times 5000$ & \\
\hline \multicolumn{5}{|l|}{ Hardwood: } \\
\hline \multirow[t]{4}{*}{ Oak, beech, meranti } & & & $\begin{array}{l}50 \times 50 \times 3000 \\
400 \times 400 \times 6000\end{array}$ & Construction \\
\hline & Rails & regels & $\begin{array}{l}40 \times 60 \times 3000 \\
70 \times 100 \times 6000\end{array}$ & \\
\hline & battens & Latten & $20 \times 44 \times 240$ & \\
\hline & planks & Planken & $19 \times 195 \times 250$ & \\
\hline \multicolumn{5}{|l|}{ Modified wood: } \\
\hline \multicolumn{2}{|l|}{ Accoya } & & $48 / 62 / 74 \times 100-200$ & Cladding \\
\hline \multicolumn{2}{|l|}{ Radiata pine } & & x 4200-6000 & \\
\hline \multicolumn{2}{|l|}{ Dumowood } & & $12 / 21 \times 128-170$ & \\
\hline \multicolumn{2}{|l|}{ /Lambowood } & & $\times 3000-5400$ & \\
\hline \multicolumn{3}{|l|}{ Spruce } & & \\
\hline \multirow{2}{*}{\multicolumn{2}{|c|}{$\begin{array}{l}\text { Platohout } \\
\text { Spruce, } \\
\text { Limba (fraké) }\end{array}$}} & & $23 \times 100-200$ & Cladding \\
\hline & & & & \\
\hline
\end{tabular}

\subsubsection{Panels and boards}

Wood composite boards or engineered wood products can be made from many wood sources (Table 6), although the softwoods prevail. Plywood production with veneers of birch and poplar are also common. In the fibre board production the wood particles require addition of adhesives and compression at elevated temperatures. There is a wide range of board qualities that find use in different building applications, from separation walls to cladding. In the Netherlands no commercial operating industries are currently manufacturing these wood based panels, except for Trespa HPL/HDF in Weert, who import their wood chips raw materials, and Linex Prograss in Koewacht, who are using flax shives as non-wood particles for particle board production. All other fibre boards for the building sector are imported.

Commercial boards are given in standard sizes measured in feet. Most common is $4 \times 8 \mathrm{ft}$ or $1220 \mathrm{x}$ $2440 \mathrm{~mm}$ with varying thickness. Deviating sizes also occur.

Plywood is most commonly made of birch, poplar, or softwood (spruce) wood veneer layers glued together. Particle boards are classified in accordance to SFS-EN312 standards (P1-P7) for different bending strength, modulus of elasticity, internal bond strength and swelling. The weather and water resistance is improved with melamine adhesive, while fire resistance is improved with alkyd resin. Melamine coatings are often applied. Wood chips are commonly derived from birch, beech, alder, pine and spruce. OSB is made of flakes of wood pressed and glued together with cross orientation. Most common raw materials used are pine and spruce. The quality properties of fibre boards and panels ${ }^{59}$ are given for bending, stiffness and internal bond strength.

\footnotetext{
${ }^{59}$ https://mdf-info.eu/technical/european-standards?lang=nl
} 


\begin{tabular}{|c|c|c|c|c|}
\hline Product & Wood source & Dimensions, mm & $\begin{array}{l}\text { Density, } \\
\mathrm{kg} / \mathrm{m}^{3}\end{array}$ & binder \\
\hline $\begin{array}{l}\text { Plywood } \\
\text { multiply } \\
\text { /Multiplex }\end{array}$ & $\begin{array}{l}\text { Birch, poplar, } \\
\text { Pine, spruce } \\
\text { Radiata pine, } \\
\text { Meranti, okumé }\end{array}$ & $\begin{array}{l}2440 \times 1220 \times 4 / 6 / 9 / 12 / 15 / 18 / 24 \\
\mathrm{~mm}\end{array}$ & $500-700$ & PF \\
\hline Particle board & $\begin{array}{l}\text { Birch, beech, alder, } \\
\text { pine, spruce, douglas fir }\end{array}$ & & $650-750$ & $10 \%$ UF \\
\hline MDF & $\begin{array}{l}\text { Softwood: pine spruce, } \\
\text { douglas fir } \\
\text { Hardwood; beech, birch }\end{array}$ & $\begin{array}{l}2440 \times 1220 \times 2 / 4 / 6 / 9 / 12 / 15 / 18 / \\
22 / 25 / 38 / 45 \mathrm{~mm}\end{array}$ & $600-800$ & $\begin{array}{l}9 \% \text { UF \& } \\
\text { paraffin }\end{array}$ \\
\hline & $\begin{array}{l}\text { Agroresidues: straw, } \\
\text { stalks }\end{array}$ & & & $\begin{array}{l}\text { or } \\
3 \% \text { MDI }\end{array}$ \\
\hline Tricoya & Acetylated fibre & & & \\
\hline $\mathrm{HPL} / \mathrm{HDF}$ & Pine, spruce, & $2440 \times 1220 \times 6 / 8 \mathrm{~mm}$ & $800-1400$ & PF \\
\hline OSB & Pine, spruce & & $600-680$ & UF \\
\hline Softboard & Pine spruce & & 350 & UF \\
\hline Hardboard & Softwood hardwood & $2440 \times 1220 \times 2.5-6 \mathrm{~mm}$ & 1450 & - \\
\hline $\begin{array}{l}\text { Wood wool } \\
\text { cement }\end{array}$ & Pine, spruce & $\begin{array}{l}2440 \times 610 \times 15 / 25 / 35 / 50 / 75 / 100 \\
\mathrm{~mm}\end{array}$ & $360-570$ & cement \\
\hline
\end{tabular}

\subsubsection{Species' potentials for the industry in Gelderland}

Scots pine has been planted in large-scale afforestation of heathlands and drift sands in the period 1900-1960 and is the most common species in Gelderland and the Netherlands. It is considered to be indigenous in the Netherlands. It is highly valued for nature conservation because a lot of light can reach the forest floor, facilitating the development of a herb and shrub layer. The wood is very suitable for construction purposes, but in practice not too much wood is used by the construction industry. The quality is variable, influenced by the often poor soil quality and poor genetic material. A large stock of Scots pine in the $40-50 \mathrm{~cm}$ diameter classes will be available in the multifunctional forests, but is currently hardly being harvested.

Larch is not indigenous in the Netherlands, but is valued as a light demanding species in natureoriented forests, and the wood is in high demand for the industry. No additional potential is available for this species.

Douglas fir is highly valued by both the industry for its valuable wood and the forest owner for its high productivity. It is an exotic species and is considered not to have value for nature conservation. It can regenerate abundantly, and for this reason some owners try to eradicate this species. The volume of wood in the diameter classes $50-60 \mathrm{~cm}$ is increasing fast, giving opportunities for increased wood supply of this species. However, it is unclear how much of these trees are currently harvested and if this may increase in future. Its wood will probably easily find its way to the industry.

Oak was traditionally valued for construction of farms, houses and ships, but is hardly used in construction nowadays. It is not harvested much, probably influenced by the high nature conservation value. Many oak forests consists of old coppices, with low quality stems. Large trees can yield high prices and may be used for veneer or renovation projects.

Also beech is not harvested much, leading to a large accumulation of volume in the higher diameter classes. The mobilisation scenarios did not show an increase in harvest despite this accumulation, suggesting that there is not much willingness and/or demand to harvest these trees.

NIPF Large showed a sizeable harvest potential of other broadleaves in diameter classes $30-70 \mathrm{~cm}$. This group is a mix of very different species, with very different wood quality and possible applications. Due to the low volumes per species it is less interesting for the construction industry, but rare species may yield high prices for specific purposes such as art objects and hand-made furniture.

In short: Especially Douglas fir is a species that is in demand in the current industry, and with a potential to be more harvested in diameter classes interesting for the building industry. Scots pine is also abundantly available, but less in demand and less harvested. 
The broadleaved species are not used much currently, but show an accumulation in the larger diameter classes especially for oak and beech. Innovations like gluelam may help to increase the usage of these species.

\subsection{SWOT Analysis}

The SWOT analysis focuses on the use of local wood for construction, i.e. wood from the province of Gelderland. The SWOT analysis described below is used to identify strengths, weaknesses, opportunities and threats concerning the application of local woody biomass for construction materials. Such analysis is often used to retrieve information from a business perspective, i.e. it is used to analyse how competitive the product or service is compared with alternative products and services, and what can be done to make it more competitive.

Strengths and weaknesses refer to internal characteristics, whereas opportunities and threats refer to external elements i.e. important issues on which the company or organisation has no influence. Our point of view is the supply chain supplying local wood for the production of building materials, wherewith local refers to the province Gelderland. Based on the SWOT the main issues are identified and next possible strategies and actions are formulated.

Strengths:

- Gelderland is the most wooded province in the Netherlands.

- $\quad$ There is already a labour force working in the biobased economy in Gelderland, especially in the paper industry and in forest conservation. And there are many saw mills, though they are relatively small.

- The availability of knowledge centres in the province in areas such as sustainable and green chemistry, life cycle analysis, ecology, biobased materials \& products and bioprocessing technologies.

- $\quad$ There are already several initiatives concerning biobased building materials in Gelderland. This includes two companies that produce innovative modified wood products, Accoya wood and Plato wood.

- The province of Gelderland implements strategies on promoting biobased economy and stimulates valorization in the region. For example, the Circular Atlas (2019) focusses, among others, on replacement of primary and finite resources by biobased resources. The province focuses on creation of value chains where every initiative should have two or more partners working together. This is increasingly possible because economically profitable business cases emerge.

\section{Weaknesses:}

- $\quad$ Though Gelderland is the province with most forest in the Netherlands, it has limited amount of forest compared with many foreign regions, e.g. in Scandinavia and Eastern Europe. The economies of scale are in favour of foreign regions and this will be hard to change. Some consequences:

- Local wood production is not cost competitive (even not compared with foreign wood which is sustainable harvested, e.g. FSC or PEFC certified). ${ }^{60}$

- Dutch wood has relatively high expenses on transport, storage etc. due to limited scale In the Dutch round wood supply chain the costs for transportation may amount to $20 \%$ to $40 \%$ of the timber value at the gate of the processing plant.

- The economic performance of Dutch private forest companies is in most years negative. ${ }^{61}$

\footnotetext{
${ }^{60}$ Kuiper, Leen, 2006. SWOT-analysis of the Dutch forest exploitation sector, Probos, September $18,2006$.

${ }^{61}$ Silvis en Voskuilen, 2018. Bedrijfsuitkomsten in de Nederlandse particuliere bosbouw over 2016
} 
- $\quad$ RIS3 (2014-2020) emphasises the importance of the use of biomass for a transition towards a more sustainable economy. However, the new RIS (2021-2027) has no focus anymore at Biobased Economy or Circular Economy. It is a policy that supports companies in food(tech), materials(tech) and health (medtech). Policies on biobased valorisation seem to have less attention in the province than some years ago. This is not supportive for biobased innovations and specializations, as they take time and need long term support and strategic decision making.

- Different policy documents provide different directions for forest management (harvesting, recreation) and there is no integrated vision of how to combine these policy goals.

- The supply of local wood is limited, and it will be difficult to increase the supply in future. Not all forest owners have the intention to harvest wood as part of their business model, even not all forest owners focus on profitability. They may favour other functions of the forest above wood production, such as landscape benefits, nature conservation and recreation. ${ }^{62}$

- Local wood types cannot satisfy all the demands from applications in building industry. The workability aspects are important for the selection of the species and are strongly dependent on the density, the homogeneity of the wood, and the mechanical properties (flexibility, dimension stability, etc.). Furthermore, local timber is often more expensive than imported wood mainly due to the small scale of operations.

- $\quad$ There is no local infrastructure for manufacturing fibre boards, particle boards, etc.

- Wood from landscape maintenance is now mainly used for energy production, which is a lowvalue application. More than $75 \%$ of the harvested wood in the Netherlands is used as fuelwood. ${ }^{63}$

\section{Opportunities:}

- $\quad$ European policy towards circular biobased economy, e.g. European Green Deal, is in favour of circular, more added value applications of biomass such as wood.

- There is increased attention to the benefits of using wood in relation to combating climate change (Actieplan Hout) and a new national policy (Bossenstrategie) is being developed, aiming for $10 \%$ more forest area in the Netherlands by 2030.

- $\quad$ Reuse of wood from demolished buildings offers possibilities. It is important to set up a materials marketplace for used wood, combined with materials passports. It is important before demolishing to take stock of which materials are available and how to extract and collect them from the building.

- Circular farming, especially when it involves agroforestry and new crops, offers opportunities. In this way biomass can be produced by agriculture.

- National policy towards circular economy and implementation of Green Deal and advice of SER (Dutch Social Economic Council) ${ }^{64}$ on biological resources support use of biomass for biobased products instead of energy.

- There is increasing demand for local products.

- Nature conservation organisations are paying more and more attention to the sales of wood and residual woody products.

- $\quad$ Some forest owners and entrepreneurs manage to sell woody products labelled as locally produced and get a higher price.

Threats:

- Timber is being traded widely across the countries' boundaries, with a high influence of the international market on wood prices. The Dutch roundwood processing industry is subject to competition from similar industries abroad. The demand for (the same) roundwood is impacted by players on an international market. This means e.g. that some of the Dutch saw logs of oak are actually being transported to China instead of being processed in The Netherlands; Dutch poplar logs go to Morocco and Dutch beech logs to Denmark. ${ }^{60}$

\footnotetext{
${ }^{62}$ Spijker et al, 2020. Marktverkenning biomassareststromen hout uit landschap

${ }^{63}$ https://ec.europa.eu/eurostat/statistics-explained/index.php/Wood_products_-_production_and_trade

${ }^{64}$ SER (Social and Economic Council), 2020. Biomass in the balance. Adivsory Report 20/07. Den Haag
} 
- $\quad$ European policy towards renewable energy, especially Renewable Energy Directive, diverts biomass towards energy production. The SER recently concluded that the use of biomass for energy production is not desirable and should be limited. ${ }^{64}$ On the other hand, the quality of the (woody) biomass used for energy production may be insufficient for construction purposes.

- Nature conservation policies (provincial, national and European) and guidelines limit the possibilities for wood production. Nearly half (46\%) of the forest in Gelderland is subsidised under a nature conservation subsidy scheme that imposes restrictions on harvesting. So even if the resource is apparently there, it may be difficult or impossible to mobilise. Summer fellings are prohibited during the breeding season in most areas, which is problematic for the industry that usually needs a constant supply. Nature conservation policies actually led to a decrease in forest area in the Netherlands in recent years, due to the focus on creating more open nature as part of the Natura2000 targets. ${ }^{65}$

- The public opinion is not always favourable towards harvesting trees. Harvesting may lead to opposition and protest. Clear communication is needed, which increases the costs.

- $\quad$ One of the easy measures to increase carbon storage in the forest in the short term is to stop harvesting. This may be considered an attractive measure for policy makers or specific NGOs, but ignores the long term effects and leakage in- or outside the country, i.e. the harvesting will simply be more intensive elsewhere with no net effect for climate change mitigation. However, it may be difficult to communicate the pros and cons effectively.

- $\quad$ There are concerns that wood harvesting and extraction of logging residues will lead to a depletion of nutrients, especially at poor sandy soils. Currently the advice is to refrain from extracting residues on poor sandy soils.

- Building regulations (e.g. vapor barrier, fire safety) hinder the use of wood and biobased materials in building projects or artificial installations need to be used for mechanical ventilation to reach the indoor climate targets for buildings like required for conventional (fossil) non-breathing materials.

- $\quad$ Current large-scale construction methods are very competitive and save as much as possible on material costs and labor. A new competing product must be both cheaper to build and easier to install. Experimental products cannot compete yet and are considered of higher risk for the constructor. Furthermore, many of the alternative biobased products are not (yet) registered in the NMD (National Milieu Database) and therefore challenging to be a product of choice in a building project due to default surcharge on environmental impact.

Given the SWOT analysis, the main issues are:

- Compared with foreign regions, the province Gelderland has a limited amount of forest. Due to economies of scale, facilities to collect, store and process wood are not cost competitive and therefore limited in the Netherlands. This will be hard to change. Moreover, the forest has other functions that it should fulfil, which may compete with the wood production function. The driver may be external in the form of policies, or internal as the aims of the forest owner (e.g. nature or landscape).

- $\quad$ There are perverse incentives in policy: due to policies concerning renewable energy (RED) (woody) biomass is diverted for energy production instead of more valuable uses such as construction materials.

Possible strategies to improve the supply of wood and woody products from Gelderland are:

- Increase scale in order to become more cost competitive by

- Increasing forest surface (e.g. as part of the EU Green Deal) and improve use of existing forest, residual streams, recycled wood, etc.

- Bundling streams of different suppliers. For the construction sector stocks are important, as well as standardisation of varieties and size. Therefore, more cooperation within the chain is needed, e.g. by setting up biomass yards where biomass is classified and pre-processed into intermediate products. ${ }^{62}$

\footnotetext{
${ }^{65}$ Schelhaas MJ, Arets EJMM, Kramer H, 2017. Het Nederlandse bos als bron van CO2. Vakblad Natuur Bos Landschap 6-9.
} 
- For this making information available for potential users on stock of timber for the market is essential. Providing centralized distribution of locally produced (certified) sawn wood and a market web-shop for quality graded timber will facilitate the commercialization.

- Since it is unlikely that huge amounts of woody biomass at low costs can be provided, it may be preferential to focus on high-quality products in lower quantities.

- Create a market for (certified) local wood for which an additional price can be requested (similar to organic products). Focus on specialized wood products (similar to specialized paper). Support for branding of local produce and a premium for lower $\mathrm{CO}_{2}$ emission (less transportation distance) in a building project could promote wood for Gelderland for construction.

- The abundantly available wood species (oak, beech, poplar etc.), which currently are underutilized in construction, because of availability, price or workability, could be promoted in certain selected uses.

- In alignment with the SER (Dutch Social Economic Council) advice, it is required to stop subsidising the use of biomass for production of energy and promote cascading use of biomass.

- As a launching customer, the government can adjust its purchasing policy and, when purchasing numerous woody products, can set requirements regarding their origin i.e. preference for local.

- Investment in innovations to make higher quality products from the same supply streams, e.g. innovations to upgrade residual streams, recycled wood, branches, wood fibers, etc. Technology development is required for processing lower quality wood into useful intermediates. ${ }^{62}$

- The demand for wood products with higher performance such as Accoya, Platowood, Nobelwood, Thermowood etc. in building applications is expected to increase. The expansion potential of local wood use in their production should be investigated. This could be an opportunity for investment.

- Investment in technologies to produce new, biobased materials from combined biomass waste streams (wood chips, shredded wood, cuttings, reed, used wood etc), with different qualities, structures and diversities.

- Awareness raising and new narratives are important aspects of the transition. The narrative should be: Growing of wood to be used in construction is positive, because of replacement of non-sustainable materials in the construction sector and the long term storage of carbon in housing. 


\section{Conclusions}

The report provides information about the amount of local wood that could be sustainably supplied for use in construction industry, possibilities of the use of wood for biobased building materials and matching of the local wood supply to the demands of the building applications. Furthermore, the hurdles and gaps faced for the increased implementation of biobased building materials and for increasing the circularity of the building industry are identified. Subsequently SWOT analysis has been executed to identify strengths, weaknesses, opportunities and threats concerning the application of local woody biomass for construction materials, while considering the entire market chain from local (province of Gelderland) wood supply to woody products utilisation.

The main aspects related to expanding the production and utilisation of local wood in the building and construction sector are:

Strength: The province Gelderland is the most wooded province in the Netherlands. Furthermore, there is already a labour force working in the biobased economy and knowledge centres are present in the province. The Circular Atlas of the province promotes use of biobased products

Weakness: Gelderland has limited forest area compared with many foreign regions, e.g. in Scandinavia and Eastern Europe. The economies of scale are in favour of these regions where large scale production is possible. As a consequence, Dutch wood is relatively expensive. Also the producers for making construction products out of wood is limited.

Opportunities: Policies towards circular biobased economy, both on European and national levels, point at valuing circular, more added value applications for wood. At the same time, in the market we see an increasing demand for (locally produced) wood and woody products.

Threats: At the other hand, Renewable Energy Directive in European Union, diverts biomass towards energy production. Furthermore, Dutch policies towards nature conservation imposes restrictions on harvesting wood.

Identified possible strategies to improve the supply of wood and woody products from Gelderland are:

- Increase supply of wood by increasing forest surface, e.g. as part of the EU Green Deal and bundling streams through cooperation within supply chains

- $\quad$ Focus on high-quality low volume products, branding as locally produced for differentiation in the marker. Consideration of specialized applications with the available wood species

- Investment in facilities and infrastructure for production of building materials from (local) wood

- $\quad$ Stimulate innovations to make quality products from residual streams (branches, pruning) and waste wood

- Investigate use of local wood in high performance wood products such as Accoya, Platowood, Nobelwood, Thermowood.

- Promotion and aware raising on benefits of use of biomass for materials and cascading use of biomass for carbon storage and resource efficiency 


\section{Acknowledgements}

The authors would like to acknowledge funding from the Wageningen University Knowledge Base programme: Towards a circular and climate positive society (Project KB-34-012-002: Sustainable lignocellulosic biomass supply for the circular biobased economy) that is supported by finance from the Dutch Ministry of Agriculture, Nature and Food Security. 



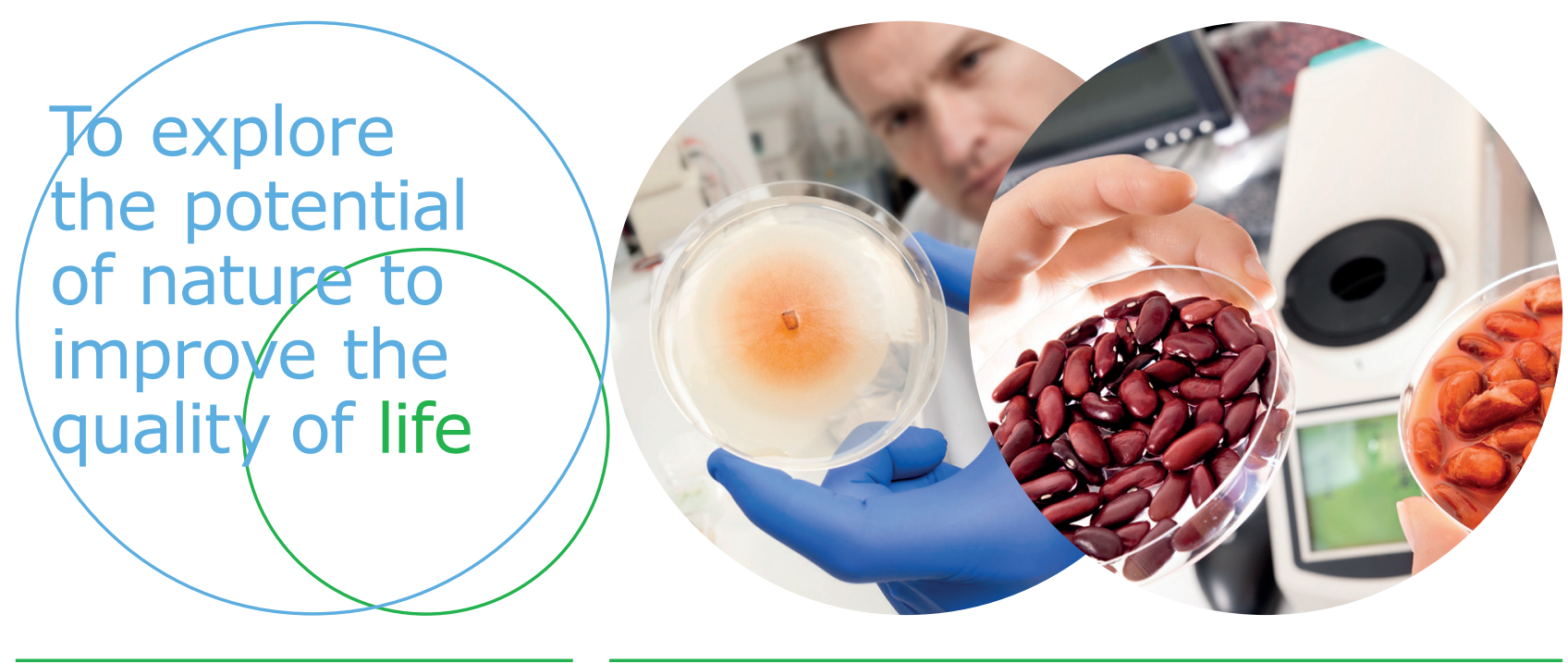

Wageningen Food \& Biobased Research Bornse Weilanden 9

6708 WG Wageningen

The Netherlands

www.wur.eu/wfbr

E info.wfbr@wur.nl

Report 2238
The mission of Wageningen University \& Research is "To explore the potential of nature to improve the quality of life". Under the banner Wageningen University \& Research, Wageningen University and the specialised research institutes of the Wageningen Research Foundation have joined forces in contributing to finding solutions to important questions in the domain of healthy food and living environment. With its roughly 30 branches, 6,800 employees (6,000 fte) and 12,900 students, Wageningen University \& Research is one of the leading organisations in its domain. The unique Wageningen approach lies in its integrated approach to issues and the collaboration between different disciplines. 